\title{
DÜBLIN
}

Technological University Dublin

ARROW@TU Dublin

\section{Carbon-based interlayers in perovskite solar cells}

Aleksandr P. Litvin

ITMO University, litvin88@gmail.com

Xiaoyu Zhang

Jilin University

Kevin Berwick

Technological University Dublin, kevin.berwick@tudublin.ie

See next page for additional authors

Follow this and additional works at: https://arrow.tudublin.ie/engscheleart2

Part of the Energy Systems Commons, Environmental Engineering Commons, Other Civil and

Environmental Engineering Commons, Power and Energy Commons, and the Transportation Engineering

Commons

\section{Recommended Citation}

Aleksandr P. Litvin, Xiaoyu Zhang, Kevin Berwick, Anatoly V. Fedorov, Weitao Zheng, Alexander V. Baranov, Carbon-based interlayers in perovskite solar cells, Renewable and Sustainable Energy Reviews, Volume 124, 2020, 109774, ISSN 1364-0321, DOI: 10.1016/j.rser.2020.109774.

This Article is brought to you for free and open access by the School of Electrical and Electronic Engineering at ARROW@TU Dublin. It has been accepted for inclusion in Articles by an authorized administrator of ARROW@TU Dublin. For more information, please contact arrow.admin@tudublin.ie, aisling.coyne@tudublin.ie, gerard.connolly@tudublin.ie.

Funder: Russian Science Foundation; Russian Ministry of Education 
Authors

Aleksandr P. Litvin, Xiaoyu Zhang, Kevin Berwick, Anatoly V. Fedorov, Weitao Zheng, and Alexander V.

Baranov

This article is available at ARROW@TU Dublin: https://arrow.tudublin.ie/engscheleart2/263 


\title{
Carbon-based interlayers in perovskite solar cells
}

\author{
Aleksandr P. Litvin ${ }^{\mathrm{a}, *}$, Xiaoyu Zhang ${ }^{\mathrm{b}}$, Kevin Berwick ${ }^{\mathrm{c}}$, Anatoly V. Fedorov ${ }^{\mathrm{a}}$, Weitao Zheng ${ }^{\mathrm{b}}$, \\ Alexander V. Baranov ${ }^{\text {a }}$ \\ ${ }^{\text {a }}$ Center of Information Optical Technologies, ITMO University, 49 Kronverksky Pr., Saint Petersburg, 197101, Russia \\ ${ }^{\mathrm{b}}$ College of Materials Science, Jilin University, Changchun, 130012, China \\ ${ }^{\mathrm{c}}$ School of Electrical and Electronic Engineering, Dublin Institute of Technology, Dublin 8, Ireland
}

\section{A R T I C L E I N F O}

\section{Keywords:}

Solar cells

Perovskites

Carbon nanomaterials

Graphene

Charge transport

\begin{abstract}
A B S T R A C T
Perovskites are solution-processed, high-performance semiconductors of interest in low-cost photovoltaics. The interfaces between the perovskite photoactive layers and the top and bottom contacts are crucial for efficient charge transport and minimizing trapping. Control of the collection of charge carriers at these interfaces is decisive to device performance. Here, we review recent progress in the realization of efficient perovskite solar cells using cheap, easily processed, stable, carbon-based interlayers. Interface materials including graphene, carbon nanotubes, fullerenes, graphene quantum dots and carbon dots are introduced and their influence on device performance is discussed.
\end{abstract}

\section{Introduction}

\subsection{Perovskite solar cells}

Perovskite solar cells (PSCs) are of considerable interest due to their easy fabrication via solution processing and high photoconversion efficiency, making them ideal candidates for solar-based, renewable energy technologies. Cubic lead halide perovskites are composed of a backbone of corner-sharing $\left[\mathrm{PbX}_{6}\right]^{4-}(\mathrm{X}=\mathrm{Cl}, \mathrm{Br}$, and/or I) octahedra with the cuboctahedral voids occupied by Cs, methylammonium (MA) and/or formamidinium (FA) cations (Fig. 1). The high defect tolerance of perovskites, due to the primary defect energy levels residing outside the bandgap, is the basis for their excellent device performance [1]. A range of technologically attractive physical properties including balanced carrier diffusion, high carrier mobility and long carrier lifetimes, enabling high performance in photovoltaic applications, have also been demonstrated [2].

Since Tsutomu Miyasaka and his co-workers first demonstrated the use of perovskites in solar cells in 2009, the power conversion efficiency (PCE) of devices based on this material has surpassed 24\% [3,4]. This unprecedented growth was enabled by several key discoveries and innovations. Undoubtedly, these include the implementation of perovskite-based solid-state solar cells, better known as meso-superstructured PSCs with a p-type hole conductor [5]. A schematic diagram of this normal mesoporous architecture is shown in
Fig. 2a. It was later realized that a perovskite layer can provide both electron and hole transport. Its ambipolar nature does not require a thick layer of mesoporous scaffold. This was the impetus for the development of a planar architecture of perovskite-based photovoltaic devices [6], illustrated in Fig. 2b. Based on this premise, the next logical stage of development is the introduction of an inverted planar device architecture with organic transport layers $[7,8]$ shown in Fig. 2c. Further details of the evolution of PSCs can be found in recent reviews [9-14].

Lead-halide perovskites can be classified as either organic-inorganic hybrid or all-inorganic, based on their A-site cation species. When organic cations MA, or FA, or their mixture, are employed as the A-site cations, they are referred to as organic-inorganic hybrid perovskites. When $\mathrm{Cs}^{+}$ions are employed as the A-site cations, they are regarded as all-inorganic perovskites. Changing the species of the A-site cations allows optimization of the band gap: the larger the A-site cations, the narrower the band gaps. The band edge of perovskites is determined by the $\mathrm{Pb} p$ orbital and I $p$ orbital [16]. A-site cations do not provide any significant contribution around the band edge, indicating that both organic-inorganic hybrid and all-inorganic perovskites have similar semiconductor properties and defect physics. Thus, the difference between the hybrid and all-inorganic perovskites stems mainly from the property of the A-site cation itself and the cation size, which is related to crystal structure stability. Since MA and FA are organic cations, and therefore thermally delicate, organic-inorganic hybrid perovskites suffer from poor thermal stability. Inorganic Cs cations can overcome this temperature issue, but their small size negatively impacts the phase

\footnotetext{
* Corresponding author.

E-mail addresses: litvin88@gmail.com, litvin@itmo.ru (A.P. Litvin).
} 


\begin{tabular}{|c|c|c|c|}
\hline \multicolumn{2}{|c|}{ List of abbreviations: } & FTO & Fluorine tin oxide \\
\hline PSCs & Perovskite solar cell & MA & Methylammonium \\
\hline $\mathrm{SC}$ & Solar cell & FA & Formamidinium \\
\hline PCE & Power conversion efficiency & ВCP & Bathocuproine \\
\hline ETL & Electron transporting layer & EVA & Ethylene vinyl acetate \\
\hline HTL & Hole transporting layer & OPD & $o$-phenylenediamine \\
\hline PL & Photoluminescence & PCBM & Phenyl-C61-butyric acid methyl ester \\
\hline TAS & Transient absorption spectroscopy & $\mathrm{PC}_{70} \mathrm{BM}$ & {$[6,6]$-Phenyl-C71-butyric acid methyl ester } \\
\hline CVD & Chemical vapour deposition & $\mathrm{IC}_{60} \mathrm{BA}$ & $1^{\prime}, 1^{\prime \prime}, 4^{\prime}, 4^{\prime \prime}$-tetrahydro-di $[1,4]$ methanonaphthaleno $[5,6]$ \\
\hline HOMO & Highest Occupied Molecular Orbital & & fullerene-C60 \\
\hline LUMO & Lowest Unoccupied Molecular Orbital & Spiro-ON & eTAD $2,2^{\prime}, 7,7^{\prime}$-tetrakis-(N,N-di-p-methoxyphenylamine) \\
\hline FF & Fill-factor & & 9,9'-spirobifluorene \\
\hline $\mathrm{J}_{\mathrm{SC}}$ & Short-circuit current & Li-TFSI & Lithium bis(trifluoromethanesulfonyl)imide \\
\hline $\mathrm{V}_{\mathrm{OC}}$ & Open circuit voltage & TBP & 4-tert-butylpyridine \\
\hline GO & Graphene oxide & TSHBC & Perthiolated trisulfur-annulated hexa-peri- \\
\hline rGO & Reduced graphene oxide & & hexabenzocoronene \\
\hline CNT & Carbon nanotube & PEDOT:F & SS Poly(3,4-ethylenedioxythiophene):poly \\
\hline SWNT & Single-wall nanotube & & (styrenesulfonate) \\
\hline MWNT & Multi-wall nanotube & P3HT & Poly(3-hexylthiophène) \\
\hline GQDs & Graphene quantum dots & PMMA & Poly(methyl methacrylate) \\
\hline CDs & Carbon dots & PTAA & Poly(triarlyamine) \\
\hline
\end{tabular}



Fig. 1. Cubic perovskite crystal structure. stability of all-inorganic perovskites.

At present, the most efficient PSCs are based on hybrid organicinorganic perovskites. Conventional, efficient $\mathrm{Pb}$-based compounds are environmentally unattractive, so lead free perovskites have attracted much attention for SC manufacture in recent years. Among lead-free materials, Sn-based organic-inorganic perovskites play an important role, since they demonstrate the highest efficiency [17-19]. The main limitation is the lower value of open-circuit voltage, which is more than two times smaller than that usually observed for Pb-based hybrid PSCs.

Hybrid organic-inorganic perovskites tend to be unstable and demonstrate sensitivity to moisture, oxygen, UV-radiation, and heating [20]. To address this, the use of inorganic perovskites is considered. Cs-based lead perovskites are known to possess higher stability as compared to their MA/FA counterparts. Rapid growth in the PCE of inorganic PSCs has occurred over the last few years [21], with highest values of over $16 \%$ for $\mathrm{CsPbBr}_{2}$ [22] and $\mathrm{CsPbI}_{3}$ [23] compositions. Precise tuning of halide compounds is a promising way to further improve inorganic PSC efficiency. Wang et al. have incorporated $5 \%$ of $\mathrm{Br}$ ions into a $\mathrm{CsPbI}_{3}$ film to get a final $\mathrm{CsPbI}_{2.85} \mathrm{Br}_{0.15}$ stoichiometry, and the record PCE reached $17.17 \%$ [24]. Ye at al. studied $\mathrm{CsPbI}_{3-\mathrm{x}} \mathrm{Br}_{\mathrm{x}}$ PSCs, where $\mathrm{x}$ varied from 0.3 to 0.5 [25]. The best device demonstrated a PCE as high as $18.64 \%$. Importantly, after $1000 \mathrm{~h}$ of 1 sun equivalent illumination, the PCE decrease was less than $6 \%$. However, the problem of improving the stability of PSCs through the use of inorganic compositions is far from solved. Lead-free inorganic perovskites were also considered to replace a conventional $\mathrm{MAPI}_{3}$ system, however their efficiency has not yet exceeded 5\% [26]. n-i-p mesoscopic PSCs



n-i-p planar PSCs



\section{p-i-n planar PSCs}

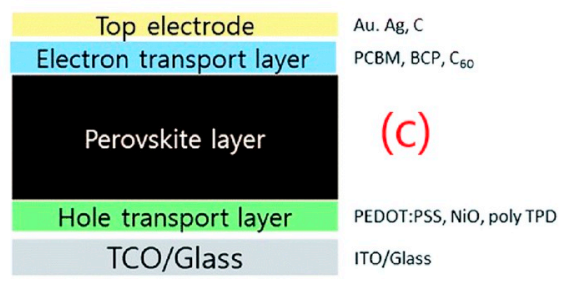

Fig. 2. Various perovskite solar cell architectures [15]. 


\subsection{Charge transporting layers}

A variety of device architectures developed quickly, a result of finding new ways to prepare the perovskite layer, optimizing the composition of the absorbing layer and developing electron- and holetransporting layers (ETL and HTL). It is important to note the influence of auxiliary layers on the formation of a high-quality, active layer, the passivation of surface defects and the protection of the active layer from exposure while using the PSC. The layer function determines the requirements for the ETL and HTL. The energy diagram of the device should be aligned for effective extraction of the required charge carriers, while blocking charges of the opposite sign. The auxiliary layers should provide a high mobility for charge carriers of the desired type, while retaining a balance in transfer rates for both carriers. Depending on the architecture of the device, the transport layer deposited on a transparent electrode must be transparent to optical radiation over a wide spectral range. Processing of the transport layer must be cheap to keep the cost of the PSC low. The effect of the coating over the active layer must also be considered. It should not cause damage, but ideally ensure the passivation of any defects formed and the long-term stability of the device [27, 28].

Materials based on carbon nanoforms played an important role in the development of perovskite-based photovoltaics, but their potential has yet to be fully realized. The fundamental function of the auxiliary layers is the extraction and transport of charge carriers. However, it soon became apparent that carbon-based transport layers could provide additional benefits by passivating the perovskite grains and protecting the active layer from moisture [29-34]. Thus, they can be a solution to several problems in perovskite solar cells, allowing not only the efficient transport of charge carriers, but also contributing to an increase in device stability and the suppression of hysteresis [35]. Often, the properties of carbon nanomaterials can be configured as required, which offers the possibility of engineering of transport layers for both electrons and holes. In this review, we focus on the implementation of carbon nanomaterials, including graphene, carbon nanotubes, fullerenes, graphene quantum dots and carbon dots, as low-cost, stable and environmental-friendly multifunctional interlayers, enabling improved charge extraction and transport and enhanced device stability.

\subsection{Optical processes at the interfaces}

Electron-hole pairs are created by illumination of a perovskite absorbing layer. Both excitons and free carriers can be formed [36]. Perovskites possess low exciton binding energies due to high dielectric screening and the small effective masses of carriers [37]. It is assumed that under SC operating conditions, free charge carriers, possibly together with weakly-bonded excitons, form in the active layer of a PSC $[36,38]$. Following their formation, the carriers must be extracted by their corresponding charge transport layers. Electrical characterization is used to determine the overall performance of the devices, which consist of a number of layers and interfaces. The efficiency of charge transfer processes between the perovskite film and charge transport layers can be measured by optical methods. The most straightforward way to estimate the efficiency of charge transfer from perovskite to charge transfer layer is to track the photoluminescence (PL) decay. Xing et al. studied time-resolved PL from an $\mathrm{MAPbI}_{3}$ film interfaced with Spiro-OMeTAD and PCBM, acting as a hole- and an electron-extracting layer, respectively [39]. PL spectra and decay curves of pristine perovskite films and those fabricated with charge transport layers are shown in Fig. 3. Clearly, PL quenching is accompanied by an acceleration of PL decay, indicating charge-carrier transfer to the corresponding extraction layers is occurring.

Changes in the PL from perovskite thin films can be used to monitor the efficiency of charge extraction by the corresponding auxiliary layer. Perovskite films formed on a $\mathrm{TiO}_{2}$ layer demonstrate shorter PL lifetimes than those on an insulating substrate. Time-resolved PL measurements can be used to verify an improvement in electron transfer by modifying a conventional ETL with carbon-based nanomaterials. Fig. 4 shows PL decay from perovskite films formed on $\mathrm{a}_{60}$ self-assembled layer (a) and on graphene quantum dots (b) both deposited on top of the $\mathrm{TiO}_{2}$ layer as compared to the PL decay on pristine $\mathrm{TiO}_{2}[40,41]$. In both cases, the additional reduction of PL lifetimes indicates a faster electron transfer and an improvement in the electron-extraction interface by the introduction of the carbon nanomaterial.

Ultrafast transient spectroscopy is a versatile tool for the analysis of processes taking place at perovskite/charge transport layer interfaces. In particular, femtosecond pump-probe transient absorption spectroscopy (TAS) is widely used to monitor photoinduced charge transfer from perovskite films to auxiliary layers [42]. The use of TAS allows detailed study of the processes occurring at both perovskite/ETL and perovskite/HTL interfaces $[43,44]$. The combination of TAS with other experimental methods allows the impact of the interface to be explored. Wang et al. combined TAS with XRD to investigate the amount of $\mathrm{PbI}_{2}$ at a perovskite/ETL interface and its influence on interface passivation [43]. Transient band edge kinetics shown in Fig. 5a demonstrate a slowdown of recombination when a compact, mesoporous $\mathrm{TiO}_{2}$ film is introduced between the FTO electrode and perovskite layer. This slowdown is attributed to the formation of a passivating $\mathrm{PbI}_{2}$ layer at the interface and was confirmed by XRD analysis. Serpetzoglou et al. combined TAS with structural and morphological characterization to study the impact of a HTL in a PSC [44]. Accelerated recombination dynamics, shown in Fig. $5 \mathrm{~b}$ and $\mathrm{c}$, were observed in a more hydrophobic PTAA as compared to a PEDOT:PSS HTL. The use of PTAA gave a smoother interface between the HTL and perovskite that boosted the final PCE of the devices.

TAS was used to explore the incorporation of carbon nanomaterials


Fig. 3. PL spectra and decay curves obtained from pristine $\mathrm{MAPbI}_{3}$ films and those covered by PCBM and Spiro-OMeTAD [39]. 

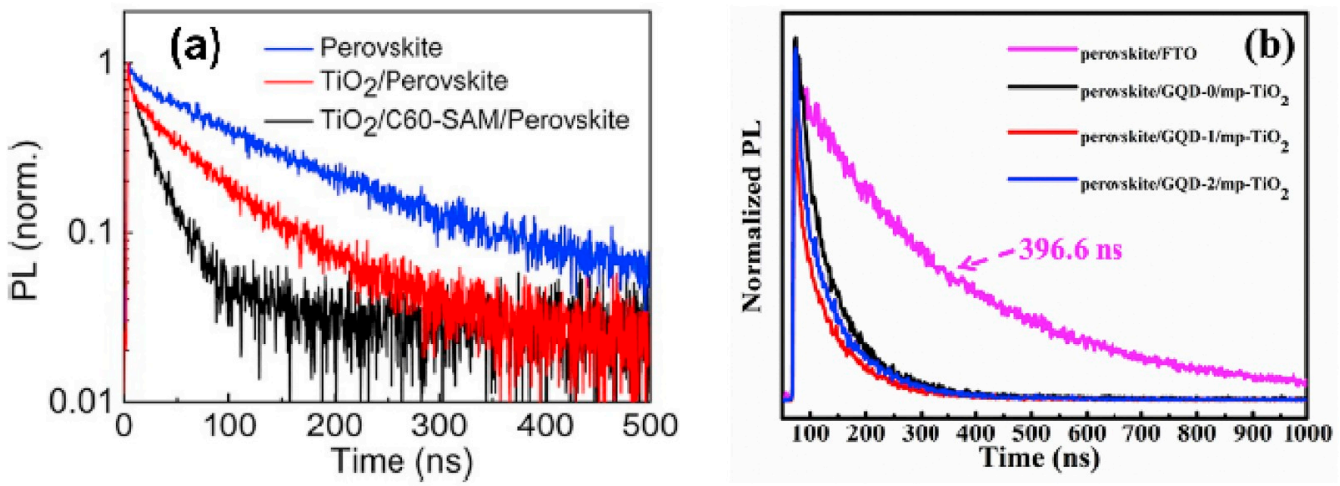

Fig. 4. PL decay from perovskite films formed on carbon nanoform modified $\mathrm{TiO}_{2} \mathrm{ETL}$ as compared to pristine perovskite and perovskite/TiO 2 [40,41].

(a)

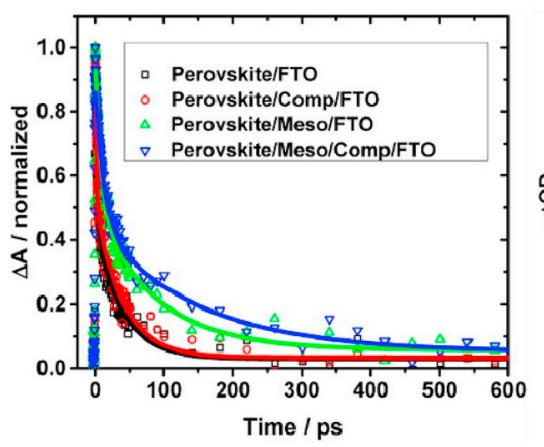

(b)

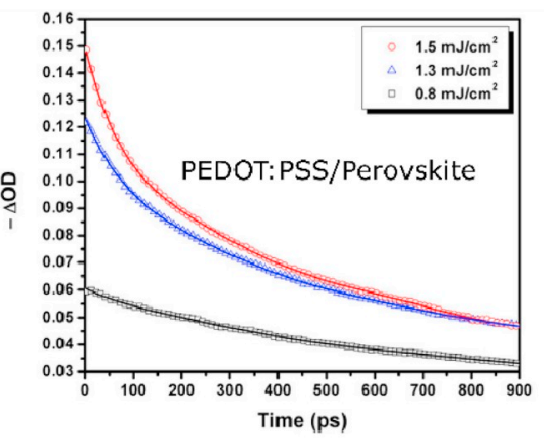

(c)

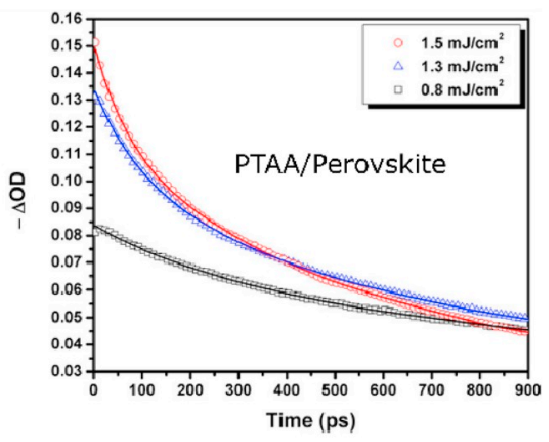

Fig. 5. Transient absorption spectroscopy reveals more efficient electron (a) and hole (b,c) extraction by the corresponding charge transfer layers [43,44].

into charge transport layers. $\mathrm{Zhu}$ et al. studied the $\mathrm{TiO}_{2} /$ perovskite interface with and without graphene quantum dots [45]. The normalized kinetic traces (Fig. 6 c-d) obtained from transient absorption spectra (Fig. 6 a-b) revealed significantly enhanced electron extraction when a thin layer of graphene quantum dots was introduced. The corresponding decay time constant reduced by three times for graphene quantum dots, as depicted in Fig. 6e and $\mathrm{f}$.

Interfaces in PSCs play an important role in defect state formation and passivation. The properties of the bottom interlayer are crucial for the formation of a high-quality perovskite crystal film. In addition to studying the structural and morphological parameters of perovskite crystals, it is possible to study local defects by optical methods at high spectral resolution. It has been shown that PL lifetime microscopy is a versatile tool to investigate perovskite grains and boundaries in detail [46-48]. Yamashita et al. combined PL microscopy, both steady-state and transient, with photocurrent imaging spectroscopy in order to demonstrate the influence of a compact/mesoporous $\mathrm{TiO}_{2}$ interlayer on perovskite layer properties [49]. They observed that PL and photocurrent maps reflect the structural inhomogeneity caused by the initial roughness of the bottom interlayer (Fig. 7). Use of advanced experimental techniques such as time-resolved PL microscopy, nanoscale photocurrent mapping and transient absorption microscopy will allow a better understanding of the processes occurring at perovskite/carbon nanomaterial interfaces.

\section{Graphene in PSCs}

\subsection{Graphene properties}

Graphene is a 2D carbon material, in which C atoms are covalently bonded to form a honeycomb lattice structure. Graphene can be prepared by mechanical, chemical, electrochemical, liquid phase exfoliation or by chemical vapour deposition (CVD) methods (Fig. 8). Largearea, highly-conductive graphene can be grown by CVD on transition metal substrates and then transferred onto a solid or flexible substrate. Exfoliation methods are usually more accessible but have several restrictions on flake size and quality [50]. A monolayer of graphene absorbs only $2.3 \%$ of incident UV-NIR light, making it promising for photovoltaic application as an auxiliary layer. The flexibility and outstanding mechanical strength of graphene are crucial for the creation of flexible optoelectronic devices. Despite its Young's module reaching $1 \mathrm{TPa}$, the reversible elongation of $\mathrm{sp}^{2} \mathrm{C}-\mathrm{C}$ bonds makes it both strong and flexible [51]. Graphene is a semi-metallic zero-bandgap semiconductor, its electrical properties are governed by $\pi-\pi$ connections between carbon atoms. The delocalized electrons originate from the out-of-plane $\pi$-bond, which governs the graphene conductivity. Their carrier mobility can reach $2 \times 10^{5} \mathrm{~cm}^{2} \mathrm{~V}^{-1} \mathrm{~s}^{-1}$ [52]. The density of states is ultralow at the Dirac point, which is favorable for tuning the graphene work function by carrier injection [53]. Both metallic and non-metallic atoms and molecules can be used for tuning the graphene work-function and conductivity type [52]. Numerous treatment procedures have been developed for the implementation of graphene derivatives in solar cells. Exfoliated graphene oxide (GO) and its reduced form $(\mathrm{rGO})$ have numerous applications in solar cell fabrication, and the reduction/oxidation degree is an additional tool to adjust graphene conductivity [34]. Table 1 lists graphene work function modifications for solar cell applications.

\subsection{Graphene as ETL}

\subsubsection{Normal mesoporous architecture}

Graphene was first introduced as an electron collecting layer in 

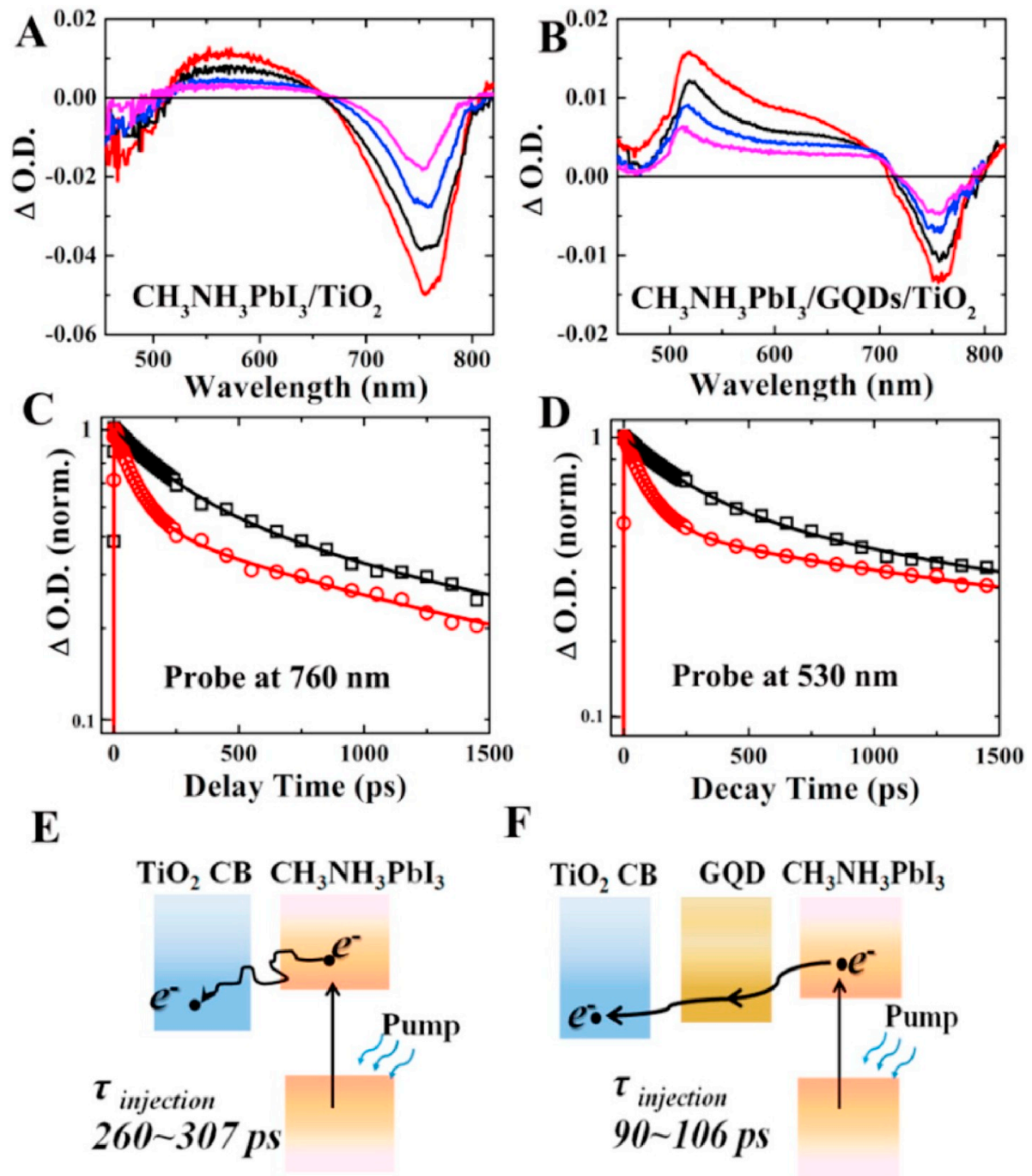

Fig. 6. TAS analysis of the $\mathrm{TiO}_{2}$ ETL modified with graphene quantum dots [45].

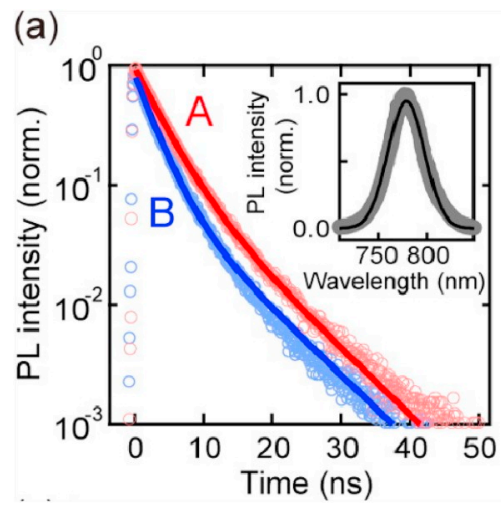

(b) $\tau_{\text {ave }}$
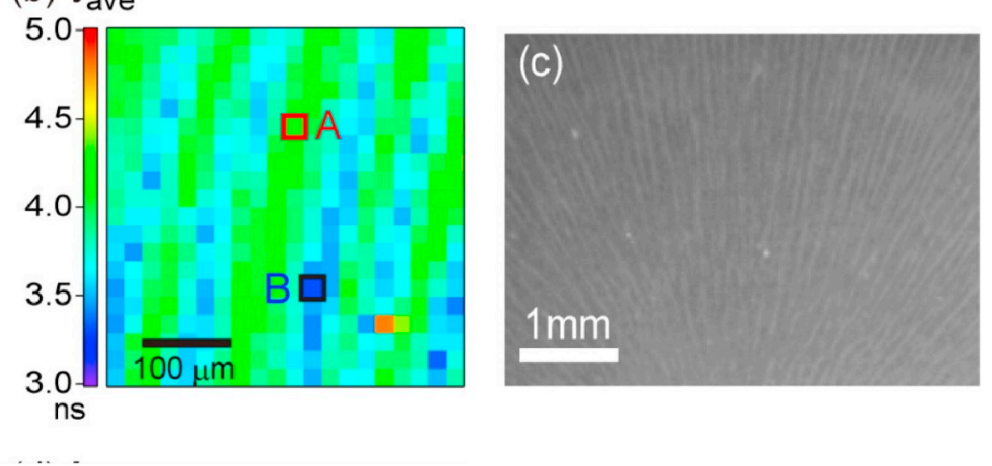

Fig. 7. PL decay curves obtained from different spatial points demonstrate different average decay times (a). The PL lifetime map (b) reflects the inhomogeneity of a bottom $\mathrm{TiO}_{2}$ interlayer (c) [49].

meso-superstructured PSCs to avoid high-temperature processing. Wang and co-workers used a nanocomposite of graphene and $\mathrm{TiO}_{2}$ nanoparticles, instead of the commonly used $\mathrm{m}-\mathrm{TiO}_{2}$, and fabricated highlyefficient devices at temperatures below $150{ }^{\circ} \mathrm{C}$ [69]. Following this, the use of graphene in a classic mesoporous PSC structure was thoroughly investigated. Han et al. optimized the volume fraction of rGO in rGO-m- $-\mathrm{TiO}_{2}$ nanocomposites and observed a reduction in interfacial resistance at the ETL/perovskite interface. A diagram of the device is shown in Fig. 9. An appropriate work function of rGO promotes efficient charge transfer from $\mathrm{TiO}_{2}$ and perovskite to the fluorine tin oxide (FTO) electrode via the highly conductive rGO. The enhanced charge collection and transfer resulted in an improvement of all key photovoltaic characteristics [70]. Argesti et al. showed that introducing lithium-neutralized graphene oxide between the perovskite and $\mathrm{m}-\mathrm{TiO}_{2}$ 
GRAPHITE

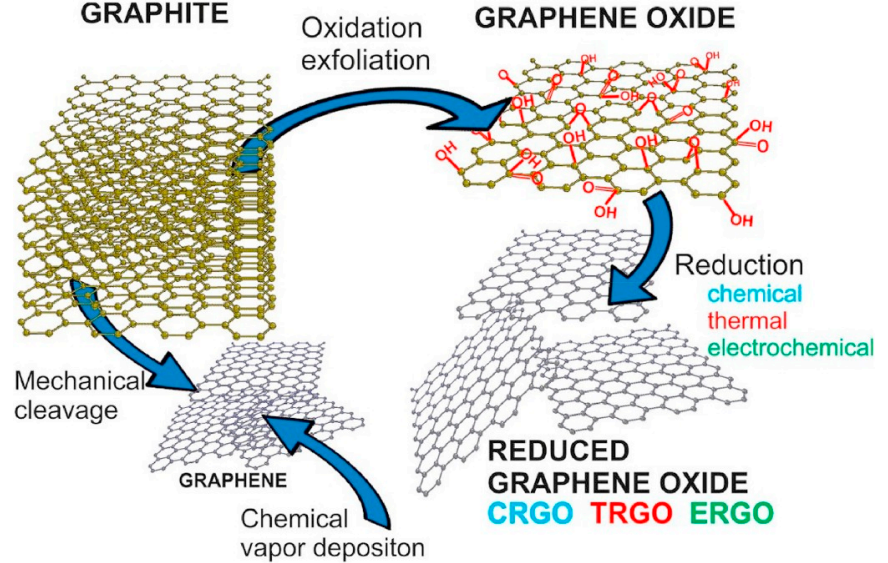

Fig. 8. Schematic illustration of possibilities for the preparation of graphene and rGO [54].

layers improves device performance and reduces hysteresis. Additional passivation of the $\mathrm{TiO}_{2}$ defects leads to enhanced device stability [57]. Li-modification is a well-known method of reducing the graphene work function for better matching to the $\mathrm{m}-\mathrm{TiO}_{2}$.

Biccari et al. investigated carrier recombination dynamics in $\mathrm{MAPbI}_{3}$ films embedded in various graphene-based ETLs for mesoporous PSCs. Four samples with $\mathrm{m}-\mathrm{TiO}_{2}$, graphene doped $\mathrm{m}-\mathrm{TiO}_{2}$ and a lithiumneutralized GO interlayer were prepared as depicted in Fig. 10. Results from both steady-state and transient PL measurements demonstrate that an additional lithium-neutralized graphene oxide (GO-Li) interlayer between the graphene-doped $\mathrm{m}-\mathrm{TiO}_{2}$ and perovskite layers causes a doubling of the efficiency of carrier collection, as compared to a conventional $\mathrm{m}-\mathrm{TiO}_{2}$ layer. An additional benefit is the improved quality of the perovskite crystal structure. The authors observed a reduction in trap density and an enhanced stability of the perovskite crystal structure, which was frozen in the tetragonal phase regardless of the tem-

O'Keeffe et al. have recently shown that incorporation of graphene flakes in the $\mathrm{m}-\mathrm{TiO}_{2}$ layer also impacts hot-carrier extraction [72]. They used femtosecond transient absorption spectroscopy to show that insertion of graphene keeps the carrier temperature after device aging. Two peaks were distinguished in the photobleaching spectra (Fig. 11), which were assigned to perovskite crystals of different sizes. The relative intensities of these peaks changed after sample aging. Faster thermalization of carriers in the aged perovskite films without a graphene additive was caused by the degradation of smaller perovskite crystals. At the same time, the introduction of graphene prevents the degradation of smaller perovskite crystals, which contribute to maintaining the hot-carrier temperature. perature [71].

\subsubsection{Normal planar architecture}

Liu et al. have demonstrated that due to the ambipolar nature of perovskite, a high PCE can be achieved when a planar heterojunction PSC architecture is used [6]. Tavakoli et al. fabricated a three-dimensional scaffold of $\mathrm{rGO}$ and inserted it between $\mathrm{TiO}_{2}$ and perovskite layers in a normal planar heterojunction structure [73]. They observed that $\mathrm{rGO}$ has a positive effect on device efficiency, stability and hysteresis suppression. As a result, a maximum PCE of $17.2 \%$ was achieved. The device demonstrated low hysteresis and better environmental stability (Fig. 12).

When ZnO nanoparticles are used as an ETL, decomposition of perovskite films during annealing can be induced by the hydroxide groups on the $\mathrm{ZnO}$ surface. To prevent this, rGO can be used as a shell around the $\mathrm{ZnO}$ nanoparticles. It was shown that the rGO layer provides $\mathrm{ZnO}$ surface passivation and enhances charge extraction [74]. Zhao et al.
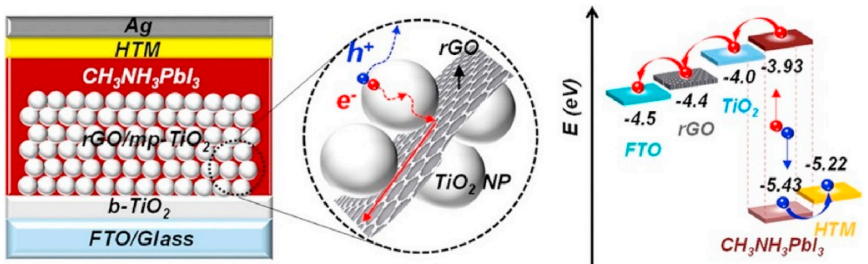

Fig. 9. Diagram of the normal mesoporous PSC with $\mathrm{rGO}^{\mathrm{m}} \mathrm{m}-\mathrm{TiO}_{2}$ ETL [70].
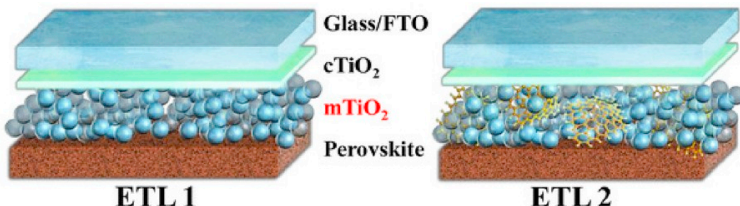

Glass/FTO

$\mathrm{cTiO}_{2}$ $\mathrm{G}+\mathrm{mTiO}_{2}$ Perovskite
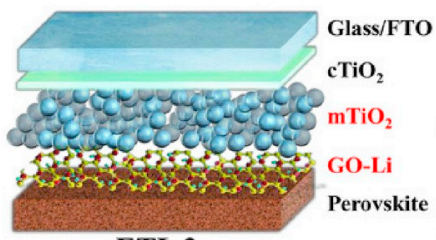

ETL 3



Glass/FTO $\mathrm{cTiO}_{2}$ $\mathrm{G}+\mathrm{mTiO}_{2}$ GO-Li Perovskite

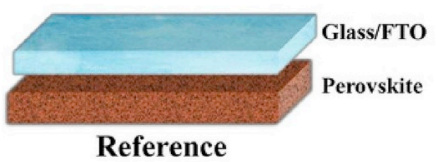

Fig. 10. The structure of the samples prepared for optimization of ETLs in planar mesoporous PSC [71].

Table 1

Tuning the graphene work function for SC application.

\begin{tabular}{|c|c|c|c|c|c|c|}
\hline Material & Work function & Treatment & Role & SC type & PCE, \% & Ref. \\
\hline GO & 4 & $\mathrm{Cs}_{2} \mathrm{CO}_{3}$ & ETL, active layer & organic & 3.67 & [55] \\
\hline rGO & 4.3 & 1-pyrenecarboxylic acid grafting & ETL, active layer & organic & 2.85 & [56] \\
\hline GO & 4.3 & $\mathrm{Li}_{2} \mathrm{CO}_{3}$ & ETL & perovskite & 11.14 & [57] \\
\hline GO & 4.68 & silver trifluoromethanesulfonate & HTL & perovskite & 11.9 & [58] \\
\hline GO & 4.8 & fuming sulfuric acid & HTL & organic & 4.37 & [59] \\
\hline CVD graphene & 4.8-4.95 & $\mathrm{AuCl}_{3}$ & HTL & perovskite & 15.9 & [60] \\
\hline $\mathrm{rGO}$ & 4.84-4.88 & p -toluenesulfonyl hydrazide & HTL & organic & 3.63 & [61] \\
\hline GO & 4.89-4.99 & $\mathrm{OsCl}_{3}, \mathrm{PtCl}_{4}$, and $\mathrm{AuCl}_{3}$ & HTL & organic & 3.54 & [62] \\
\hline rGO & 4.95 & $\mathrm{Ag}$ - microwave assisted & Active layer, hole extraction & organic & 4.23 & [63] \\
\hline rGO & 4.97 & phenylhydrazinebased reduction & HTL & organic & 6.71 & [64] \\
\hline GO & 5.2 & $\mathrm{O}_{2}$ plasma treatment & HTL & organic & 3.59 & [65] \\
\hline GO & 5.21 & photochemical chlorination & HTL & organic & 7.59 & [66] \\
\hline GO & 5.23 & photochemical chlorination & HTL & organic & 6.56 & [67] \\
\hline GO & 5.37 & $\mathrm{NH}_{3}$ & HTL & perovskite & 16.11 & [68] \\
\hline
\end{tabular}



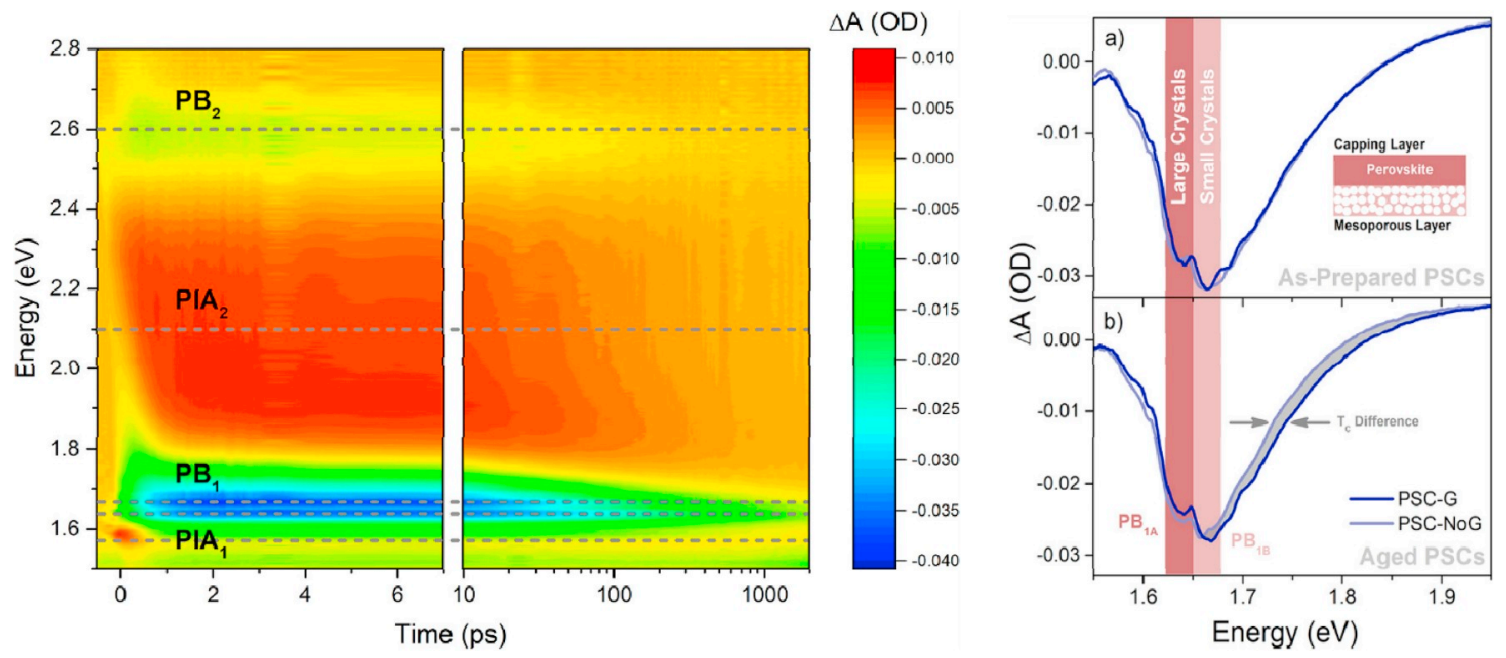

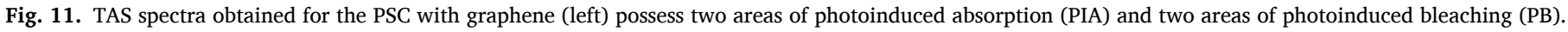
The PB1 area is composed of two distinct peaks (right) at 1.64 and $1.66 \mathrm{eV}$, corresponding to the large and small perovskite crystals respectively [72].
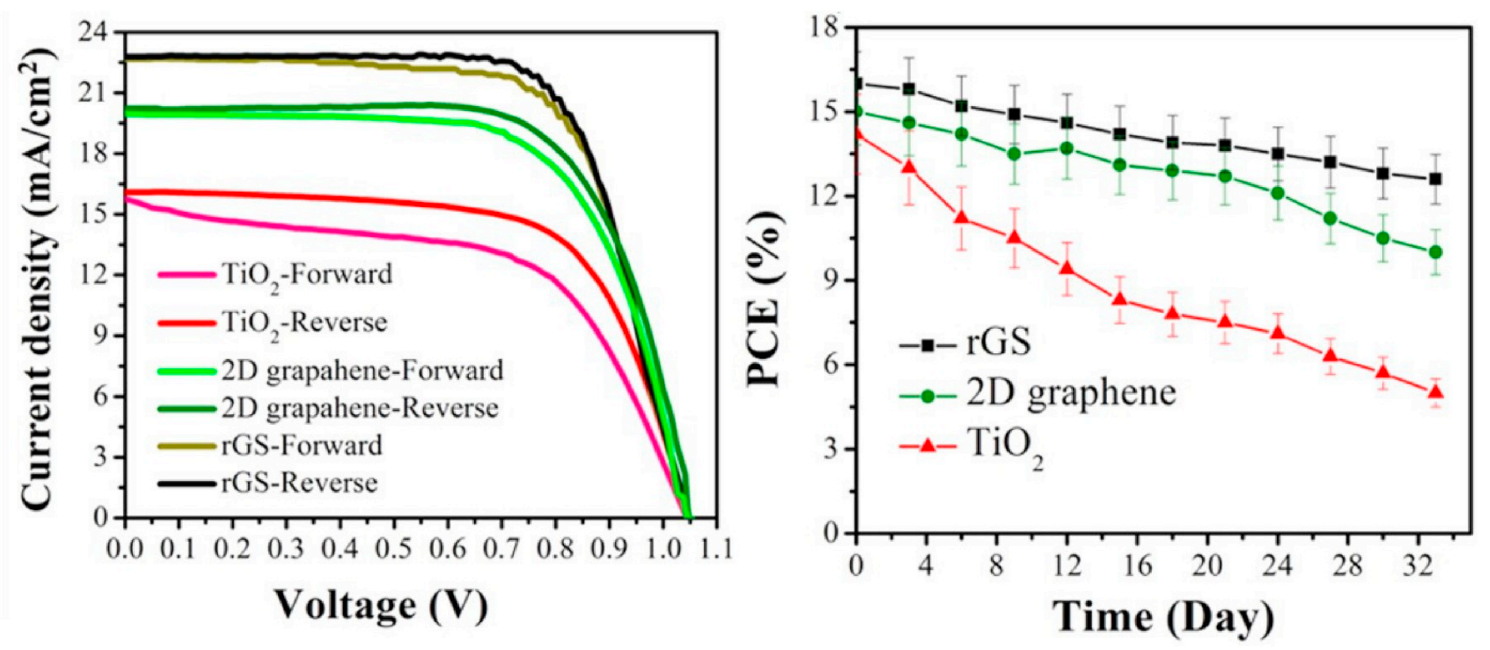

Fig. 12. The insertion of rGO-scaffold between $\mathrm{TiO}_{2}$ and perovskite layers provides higher efficiency, lower hysteresis and better stability [73].

inserted naphthalene diimide-graphene into a $\mathrm{SnO}_{2}$ nanocrystal ETL [75]. Modification of the $\mathrm{SnO}_{2}$ ETL allowed van der Waals interaction between the ETL and perovskite film that fixed the octahedral $\left[\mathrm{PbI}_{6}\right]^{4-}$. Improved electron extraction and compressed charge recombination resulted in a PCE of over 20\%. Later, Zhu et al. tested the stability of the devices with a $\mathrm{SnO}_{2}$-graphene ETL [76]. They found that graphene incorporation promotes device stability. The device lost only $10 \%$ of its initial efficiency after $300 \mathrm{~h}$ storage under humid atmospheric conditions.

\subsubsection{Inverted planar architecture}

An inverted planar heterojunction structure was also developed for PSCs. In this structure, graphene can be used in combination with PCBM and $\mathrm{TiO}_{\mathrm{x}}$. Kakavelakis et al. reduced GO using a mixture of hydriodic and acetic acids and added this to a PCBM solution at various concentrations [77]. The effect of rGO incorporation was dramatic, causing a series resistance reduction, short circuit current density growth, light soaking effect repression and perovskite crystal structure stabilization. The efficiency of the modified device increased from 12.93 to $14.51 \%$. More efficient PL quenching and accelerated recombination, as indicated by transient absorption spectroscopy, suggested improved charge carrier extraction when the rGO-modified ETL was used. As a result, the $\mathrm{J}_{\mathrm{sc}}$ value increased from 20.65 to $22.92 \mathrm{~mA} / \mathrm{cm}^{2}$. Independent measurements of conductivity for the two ETLs shows a fivefold higher value for the PCBM-rGO sample. This increase in conductivity allowed efficient transport of extracted electrons to the electrode, without causing hysteresis. Additionally, use of a PCBM-rGO ETL gave a smoother device, providing better contact with the electrode and reduced series resistance. A stability test, performed under solar illumination at $50 \%$ humidity, showed very fast degradation of the reference sample. The most pronounced changes were noticed for the $\mathrm{V}_{\mathrm{oc}}$ and $\mathrm{FF}$ values, indicating the degradation of the active layer. The device with the PCBM-rGO ETL retained a fivefold higher PCE after a $50 \mathrm{~h}$ stability test. Nouri et al. fabricated a series of devices with organic-free interlayers with graphene derivatives $[78,79]$. Li-functionalized GO was used in conjunction with sol-prepared $\mathrm{TiO}_{\mathrm{x}}$. The $\mathrm{GO}$ and $\mathrm{TiO}_{\mathrm{x}}$ did not provide adequate efficiency themselves, but formed an efficient charge funnel when used together. The introduction of hydrophobic graphene derivatives is especially important for stability improvement of the inverted planar heterojunction PSCs. Kim et al. demonstrated $82 \%$ of the initial PCE after 30 days exposure to $50 \%$ humidity [80]. To realize such a stable device, they synthesized edged-selectively fluorine functionalized graphene nanoplatelets and deposited them onto a thin layer of PCBM. The device structure is shown in Fig. 13. The edge functionalization by fluorine created a superhydrophobic fluorocarbon layer which provided protection against moisture. The results obtained by 
incorporation of graphene derivatives into the ETL for PSCs are listed in Table 2.

\subsection{Graphene as HTL}

\subsubsection{Normal architecture}

Spiro-OMeTAD [2,2',7,7'-tetrakis-(N,N-di-p-methoxyphenylamine) 9,9'-spirobifluorene] is the most common hole transport material for normal mesoporous PSCs. Insufficient charge mobility often requires additional doping of Spiro-OMeTAD, and Li-TFSI [lithium bis(trifluoromethanesulfonyl)imide] and TBP (4-tert-butylpyridine) are the most common dopants used. However, these dopants reduce the environmental stability of the HTL. It was shown that TBP can lead to corrosion of an active perovskite layer, limiting the long-term stability of devices [81]. Acetonitrile is used to dissolve Li-TFSI, however any residue of this solvent in the HTL is harmful to the perovskite layer [20]. PSCs often suffer from the hydroscopic nature of Spiro-OMeTAD-based HTLs. Li-TFSI is a highly hygroscopic dopant which has a tendency to liquify in the presence of moisture [82]. Hydrophobic graphene derivatives are understood to improve the HTLs for PSCs by increasing both charge mobility and moisture stability.

In the simplest case, graphene derivatives can be placed between an active layer and Spiro-OMeTAD. In this case, graphene derivatives can provide better hole extraction, perovskite film passivation, better wettability for Spiro-OMeTAD deposition and enhanced stability [83, 84]. Graphene derivatives have been also considered to replace unstable dopants for Spiro-OMeTAD. Luo et al. investigated GO and rGO with different degrees of reduction as an interlayer between a perovskite film and dopant-free Spiro-OMeTAD [85]. The performance achieved when using rGO greatly exceeded that obtained for GO and dopant-free samples. Despite doped Spiro-OMeTAD layers demonstrating higher performance as prepared, they suffered from a rapid worsening of their performance after storage at ambient conditions [20,82]. Conversely, a slow decrease in performance was observed for both rGO and GO samples. In a similar way, Wen et al. used amino-functionalized graphene (NGs) between an active and dopant-free Spiro-OMeTAD layer [86]. They achieved a 36\% PCE improvement as compared to the graphene-free sample. This improvement was attributed to perovskite trap state reduction and improved hole capture and transfer.

Cao et al. completely replaced Spiro-OMeTAD with a functionalized nanographene (perthiolated trisulfur-annulated hexa-peri-hexabenzocoronene, TSHBC) [87]. First, $20 \mathrm{~nm}$ of pristine TSHBC was used as the HTL, giving a PCE of $12.8 \%$. Then, two additional homologous modifications of TSHBC with slightly shifted HOMO/LUMO (Highest Occupied Molecular Orbital/Lowest Unoccupied Molecular Orbital)

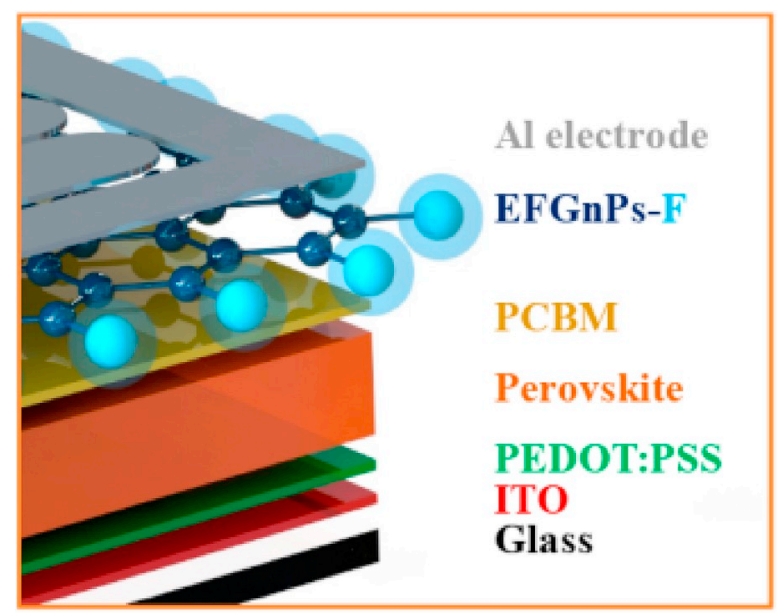

Fig. 13. The structure of the inverted planar heterojunction PSC optimized by introduction of fluorine functionalized graphene nanoplatelets [80]. energy positions were analyzed. It was found that such a shift degrades $\mathrm{V}_{\mathrm{OC}}$ and photovoltaic performance. These findings indicate the importance of precise work function tuning of graphene derivatives in order to achieve an optimal match with the perovskite film. A further increase in the PCE was achieved by incorporating highly-conductive graphene sheets into a TSHBC HTL. The addition of $20 \mathrm{wt} \%$ of graphene sheets resulted in a PCE of $14.0 \%$ and a noticeable enhancement in device stability. Devices with the TSHBC-graphene HTL retained more than $90 \%$ of their initial efficiency after 10 days of storage at ambient conditions.

Palma et al. compared the long-term efficiency of devices with SpiroOMeTAD and rGO HTLs [88]. They observed a 41\% reduction in the PCE for the Spiro-OMeTAD device after a $1987 \mathrm{~h}$ shelf life test. In contrast, the rGO-based device demonstrated a $36 \%$ increase in its PCE. The increase in PCE was attributed to a reduction of charged defects inside the active layer caused by illumination during stress test measurements. Over this period, the efficiency of the rGO device exceeded that of the Spiro-OMeTAD device.

\subsubsection{Inverted architecture}

In the inverted PSC architecture, PEDOT:PSS [Poly(3,4ethylenedioxythiophene):poly(styrenesulfonate)] is commonly used. Like Spiro-OMeTAD, PEDOT:PSS is hydroscopic and can accelerate PSC degradation. To address this problem, a thin layer of graphene can be fabricated before PEDOT:PSS deposition, which should provide better device stability. Lee et al. studied the PEDOT:PSS, GO, and GO/PEDOT: PSS HTLs in a planar inverted PSC [89]. GO/PEDOT:PSS HTL was fabricated by sequential spin-coating of GO and PEDOT:PSS solutions. A composite HTL provided superior device efficiency due to decreased series resistance and increased shunt resistance. The authors pointed out that matching of GO and PEDOT:PSS work functions promotes efficient hole transfer to the indium-tin oxide (ITO) electrode. GO also exhibited electron blocking and improved environmental stability. Importantly, the device with the pristine GO HTL demonstrated the highest stability. $\mathrm{Kim}$ et al. used $\mathrm{AuCl}_{3}$-doped graphene as an interlayer between the ITO and PEDOT:PSS [60]. A diagram of the device and a SEM cross-section are shown in Fig. 14. Variation of the amount of $\mathrm{AuCl}_{3}$ in nitromethane solution allowed tuning of the work function of graphene. A work function increase was accompanied by a reduction of charge mobility, and the highest PCE was achieved at an intermediate $\mathrm{AuCl}_{3}$ concentration. Device stability with the modified graphene was only slightly worse than that obtained for the pristine graphene, but it was much improved as compared to the PEDOT:PSS only device. A reverse sequence of layer deposition was demonstrated in the work done by Feng and co-workers [68]. A 2-nm ammonia modified graphene oxide (GO: $\mathrm{NH}_{3}$ ) layer was spin-coated onto a pre-deposited PEDOT:PSS layer. Different mixing ratios of GO solution and ammonia were tried in order to obtain the best photovoltaic characteristics. It was found that a thin layer of graphene influences the formation of an active perovskite film. The authors observed improved crystallization and a preferred orientation order of the perovskite structure. Mixing of modified graphene and PEDOT:PSS can also have a positive effect on photovoltaic characteristics, including $\mathrm{J}_{\mathrm{SC}}, \mathrm{V}_{\mathrm{OC}}, \mathrm{FF}$, serial and shunt resistance [58].

Pristine graphene derivatives have also been considered as a replacement for PEDOT:PSS HTL. As discussed earlier, one could expect a favorable perovskite morphology using these materials. Wu et al. used a thin layer of GO as the HTL and achieved a maximum PCE of $12.4 \%$, only slightly smaller than that obtained for the PEDOT:PSS HTL [90]. Yeo et al. achieved easily reproducible efficiencies of over $10 \%$ using rGO [91]. The improved perovskite crystallinity and charge collection was accompanied by a prolonged operational lifetime for the cell. Jokar has recently compared GO and rGO with different reducing agents as HTLs in an inverted planar PSC [92]. Hydrazine $\left(\mathrm{N}_{2} \mathrm{H}_{4}\right)$, sodium borohydride $\left(\mathrm{NaBH}_{4}\right)$, and 4-hydrazino benzenesulfonic acid were utilized for GO reduction to obtain rGO with different oxygen contents, as shown in Fig. 15c. It was observed that formation of a perovskite layer on a GO 
Table 2

Incorporation of graphene derivatives into the ETL for PSCs.

\begin{tabular}{|c|c|c|c|c|c|c|c|c|}
\hline Material & Location & Structure & $\begin{array}{l}\text { PCE }(\%) / \text { Jsc } \\
\left(\mathrm{mA} / \mathrm{cm}^{2}\right) / \text { Voc } \\
(\mathrm{V}) / \mathrm{FF}(\%)\end{array}$ & $\uparrow \mathrm{PCE}$ & $\uparrow$ Stability & Improvements & Year & Ref. \\
\hline $\begin{array}{l}\text { Graphene } \\
\text { flakes }\end{array}$ & $\begin{array}{l}\text { Blend with } \mathrm{TiO}_{2} \\
\text { nanoparticles }\end{array}$ & $\begin{array}{l}\mathrm{FTO} / \mathrm{TiO}_{2-} \\
\mathrm{Gr}^{\mathrm{a}} / \mathrm{Act}^{\mathrm{b}} / \mathrm{SO}^{\mathrm{c}} / \\
\mathrm{Au}\end{array}$ & $\begin{array}{l}15.6 / 21.9 / \\
1.04 / 73\end{array}$ & + & $\mathrm{n} / \mathrm{i}$ & Low-temperature processing & 2014 & [69] \\
\hline rGO & Blend with $\mathrm{m}-\mathrm{TiO}_{2}$ & $\begin{array}{l}\mathrm{FTO} / \mathrm{TiO}_{2}-\mathrm{Gr} / \\
\mathrm{Act} / \mathrm{SO} / \mathrm{Ag}\end{array}$ & $\begin{array}{l}14.5 / 22.0 / \\
0.93 / 70.7\end{array}$ & + & $\mathrm{n} / \mathrm{i}$ & $\begin{array}{l}\text { reduces interfacial resistance; improves charge } \\
\text { collection }\end{array}$ & 2015 & [70] \\
\hline Li-GO & on top of $\mathrm{m}-\mathrm{TiO}_{2}$ & $\begin{array}{l}\mathrm{FTO} / \mathrm{TiO}_{2} / \mathrm{Gr} / \\
\mathrm{Act} / \mathrm{SO} / \mathrm{Au}\end{array}$ & $\begin{array}{l}11.1 / 19.6 / \\
0.859 / 70.3\end{array}$ & + & + & $\begin{array}{l}\text { improved short circuit current and fill factor; reduced } \\
\text { hysteresis; enhanced stability under irradiation }\end{array}$ & 2016 & [57] \\
\hline $\begin{array}{l}\text { Graphene, } \\
\text { Li-GO }\end{array}$ & $\begin{array}{l}\text { Graphene doped m- } \\
\mathrm{TiO}_{2}+\mathrm{Li}-\mathrm{GO} \\
\text { interlayer }\end{array}$ & $\begin{array}{l}\mathrm{FTO} / \mathrm{TiO}_{2}-\mathrm{Gr} / \\
\text { Act }\end{array}$ & $\mathrm{n} / \mathrm{i}$ & $\mathrm{n} / \mathrm{i}$ & + & $\begin{array}{l}\text { carrier collection efficiency; improved perovskite } \\
\text { crystalline quality; smaller perovskite trap density; freezes } \\
\mathrm{MAPbI}_{3} \text { in the tetragonal phase }\end{array}$ & 2017 & [71] \\
\hline rGO scaffold & $\begin{array}{l}\text { Between } \mathrm{TiO}_{2} \text { and } \\
\text { active }\end{array}$ & $\begin{array}{l}\mathrm{FTO} / \mathrm{TiO}_{2} / \mathrm{Gr} / \\
\mathrm{Act} / \mathrm{SO} / \mathrm{Au}\end{array}$ & $\begin{array}{l}17.2 / 22.8 / \\
1.05 / 72\end{array}$ & + & + & device efficiency, stability and hysteresis suppression & 2016 & [73] \\
\hline rGO & $\begin{array}{l}\mathrm{ZnO@rGO} \\
\text { core@shell }\end{array}$ & $\begin{array}{l}\mathrm{FTO} / \mathrm{ZnO}-\mathrm{Gr} / \\
\mathrm{Act} / \mathrm{SO} / \mathrm{Au}\end{array}$ & $\begin{array}{l}15.2 / 21.7 / \\
1.03 / 68\end{array}$ & $\mathrm{n} / \mathrm{i}$ & + & ZnO surface passivation; enhanced charge extraction & 2016 & [74] \\
\hline $\begin{array}{l}\text { NDI- } \\
\text { graphene }\end{array}$ & Blend with $\mathrm{SnO}_{2}$ & $\begin{array}{l}\mathrm{FTO} / \mathrm{SnO}_{2}-\mathrm{Gr} / \\
\mathrm{Act} / \mathrm{SO} / \mathrm{Au}\end{array}$ & $\begin{array}{l}20.16 / 22.66 / \\
1.084 / 82.1\end{array}$ & + & $\mathrm{n} / \mathrm{i}$ & $\begin{array}{l}\text { Improved electron extraction; compressed charge } \\
\text { recombination }\end{array}$ & 2018 & [75] \\
\hline graphene & Blend with $\mathrm{SnO}_{2}$ & $\begin{array}{l}\mathrm{FTO} / \mathrm{SnO}_{2}-\mathrm{Gr} / \\
\mathrm{Act} / \mathrm{SO} / \mathrm{Au}\end{array}$ & $\begin{array}{l}18.11 / 23.06 / \\
1.091 / 72\end{array}$ & + & + & $\begin{array}{l}\text { Enhanced carrier; suppressed interfacial charge } \\
\text { recombination; retention of } 90 \% \text { of the initial PCE after } \\
300 \text { h aging in } 40 \pm 5 \% \text { humidity }\end{array}$ & 2018 & [76] \\
\hline rGO & Blend with PCBM & $\begin{array}{l}\text { ITO/PP } / \text { Act/ } \\
\text { PCBM-Gr/Ag }\end{array}$ & $\begin{array}{l}13.5 / 22.24 / \\
0.866 / 64.7\end{array}$ & + & + & $\begin{array}{l}\text { reduced series resistance and surface roughness; increased } \\
\text { short circuit current density; reduced light soaking effect; } \\
\text { stabilization of perovskite crystal structure after prolonged } \\
\text { illumination }\end{array}$ & 2017 & [77] \\
\hline Li-GO & Between $\mathrm{TiO}_{\mathrm{x}}$ and $\mathrm{Al}$ & $\begin{array}{l}\mathrm{FTO} / \mathrm{Gr} / \mathrm{Act} / \\
\mathrm{TiO}_{\mathrm{x}} / \mathrm{Gr} / \mathrm{Al}\end{array}$ & $\begin{array}{l}10.2 / 15.6 / \\
0.91 / 72\end{array}$ & + & $\mathrm{n} / \mathrm{i}$ & Improved electron transport and current & 2017 & [78] \\
\hline Li-GO & Between $\mathrm{TiO}_{\mathrm{x}}$ and $\mathrm{Al}$ & $\begin{array}{l}\mathrm{FTO} / \mathrm{Gr} / \mathrm{NiO} / \\
\mathrm{Act} / \mathrm{TiO}_{\mathrm{x}} / \mathrm{Gr} / \\
\mathrm{Al}\end{array}$ & $\begin{array}{l}11.2 / 17.7 / \\
0.96 / 61\end{array}$ & - & + & Improved stability at ambient conditions & 2017 & [79] \\
\hline EFGnPs-F & $\begin{array}{l}\text { Between PCBM and } \\
\mathrm{Al}\end{array}$ & $\begin{array}{l}\text { ITO/PP/Act/ } \\
\text { PCBM-Gr/Al }\end{array}$ & $\begin{array}{l}14.3 / 18.5 / \\
0.98 / 78\end{array}$ & - & + & $82 \%$ of initial PCE after 30 days exposure to $50 \%$ humidity & 2017 & [80] \\
\hline \multicolumn{9}{|c|}{$\begin{array}{l}\text { a graphene derivative } \\
\text { b active layer } \\
\text { c Spiro-OMeTAD } \\
\text { d PEDOT:PSS }\end{array}$} \\
\hline
\end{tabular}


Fig. 14. The schematic image, band diagram, and SEM cross-section of the inverted planar heterojunction PSC with an additional protective $\mathrm{AuCl}_{3}$-doped graphene layer [60].

surface leads to the most pronounced quenching of the PL intensity and a decrease in the PL lifetime, as compared to rGO samples (Fig. 15a and b). That was ascribed to the most efficient hole extraction by GO HTL. It was shown that the oxygen content drastically influences the hole-extraction rate. Hence, oxygen-rich GO provided the fastest hole extraction. However, the dependence of the hole-extraction rate contrasted with that observed from photovoltaic measurements. Thus, hole transfer from the HTL to the ITO became a bottleneck, inducing parasitic charge recombination at the perovskite/HTL interface. Precise tuning of the oxygen content during rGO reduction allows a balance to be achieved between hole extraction and transfer. The results obtained by incorporation of graphene derivatives into the HTL for PSCs are listed in Table 3.

\section{Fullerenes in PSCs}

\subsection{Graphene properties}

Fullerene is another carbon allotrope which finds broad application in optoelectronics. Pristine fullerenes contain a specific number $\left(\mathrm{C}_{60}\right.$, $\mathrm{C}_{70}$ etc.) of $\mathrm{C}$-atoms, covalently bonded to three neighboring atoms. Fullerenes can be functionalized to obtain desired chemical and physical properties, with $\mathrm{PC}_{60} \mathrm{BM}$ ([6,6]-Phenyl-C61-butyric acid methyl ester) and $\mathrm{PC}_{70} \mathrm{BM}([6,6]$-Phenyl-C71-butyric acid methyl ester) as typical examples. Fullerene derivatives can be easily dissolved in nonpolar organic solvents, allowing the possibility of using them as an electron acceptor for semiconducting polymers in organic photovoltaics. Solution-processability and satisfactory power conversion efficiencies of these hybrid materials encouraged the growth of organic photovoltaics. Apart from the fullerene/polymer system, fullerene derivatives have been considered as an electron-accepting material which can additionally enhance charge separation and electron transfer. Fullerenes have been intensively studied as an electron-transport material for both normal and inverted SCs. It was found that the function of fullerene in SCs is not limited to direct improvement of the principal photovoltaic characteristics, they can also enhance stability and reduce $\mathrm{J}-\mathrm{V}$ hysteresis. 

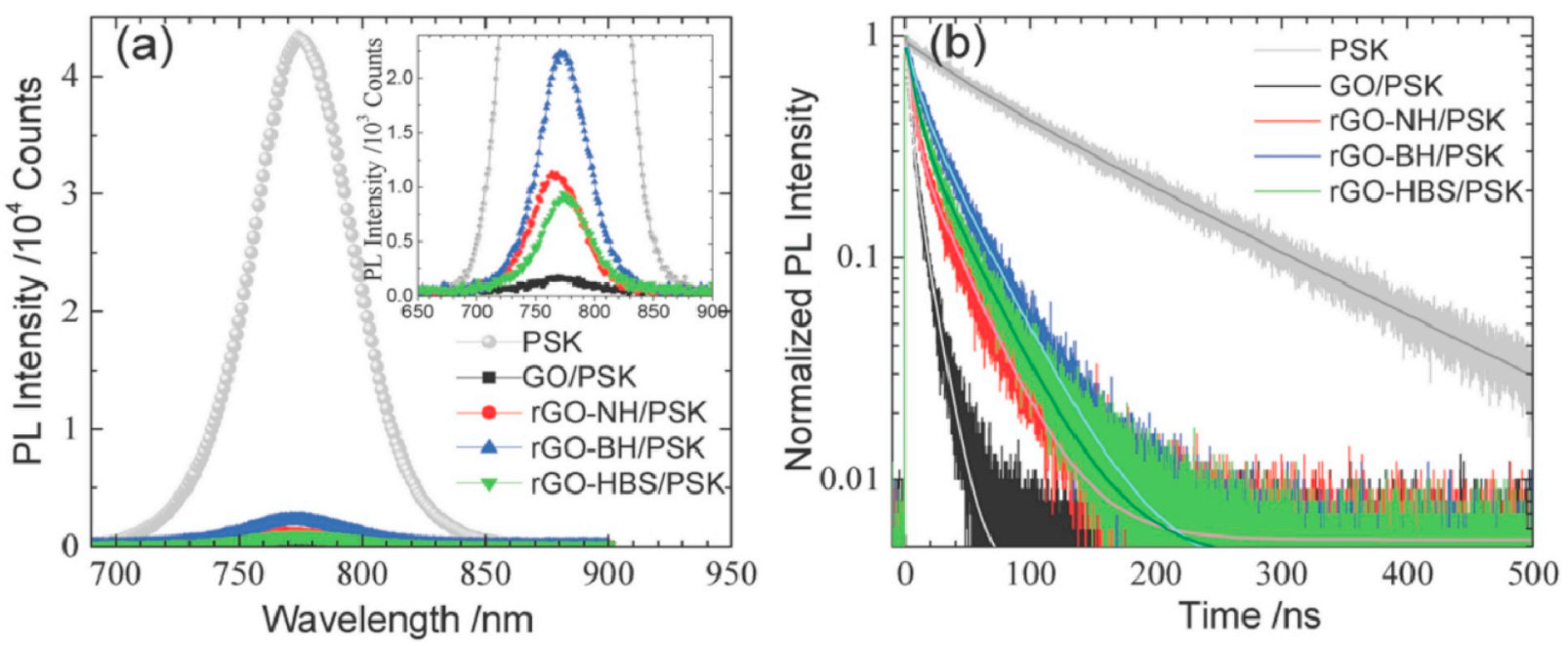

(c)

Graphene oxide (GO)

by Hummers method
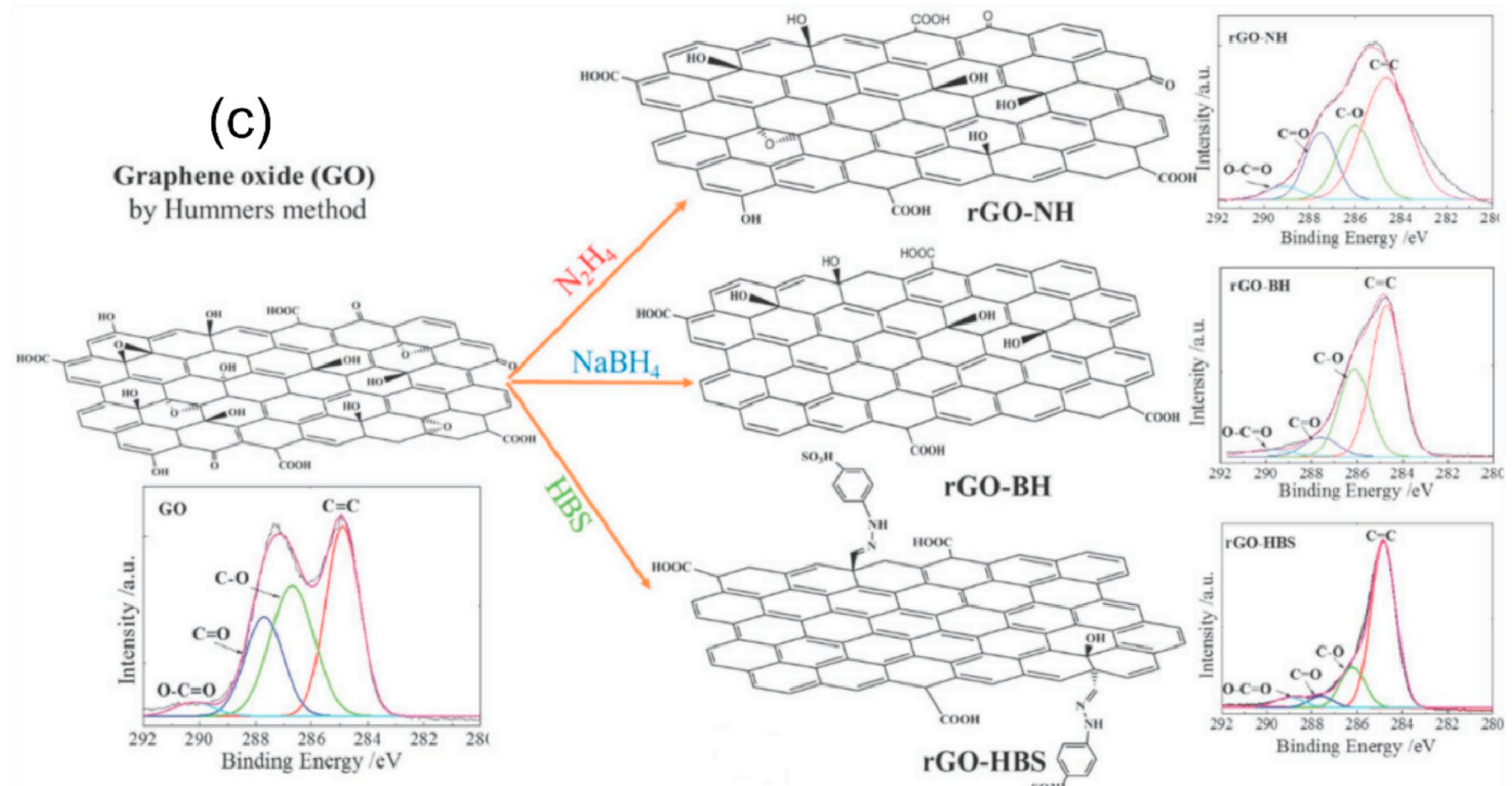

rGO-BH
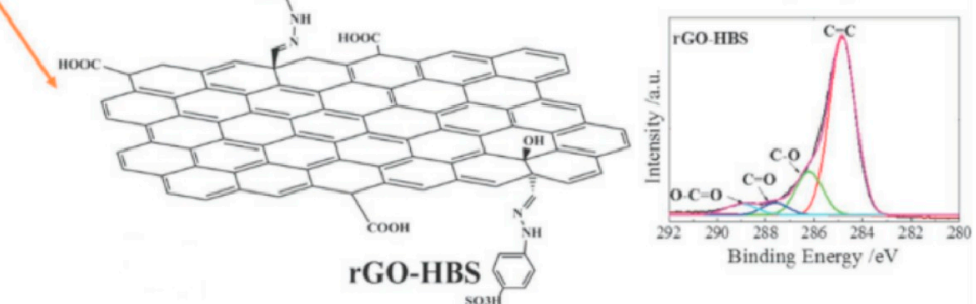

Fig. 15. Stronger quenching of PL intensity (a) and reduction of PL lifetimes (b) indicate more efficient hole extraction with GO. (c) Reduction of graphene with various reducing agents affected the oxygen content in the HTL layer of an inverted planar heterojunction PSC as confirmed by XPS measurements [92].

\subsection{Inverted architecture}

Jeng et al. demonstrated a perovskite/fullerene inverted planar heterojunction PSC for the first time in 2013 [7]. In this pioneering work, a thin layer of fullerene $\left[\mathrm{C}_{60}, \mathrm{PC}_{60} \mathrm{BM}\right.$, or $\mathrm{IC}_{60} \mathrm{BA}\left(1^{\prime}, 1^{\prime \prime}, 4^{\prime}, 4^{\prime \prime}\right.$-tetrahydro-di [1,4]methanonaphthaleno [5,6]fullerene-C60)] was thermally deposited onto perovskite crystals. The planar heterojunction was sandwiched between an ITO/PEDOT:PSS and BCP (bathocuproine)/Al anode and cathode and exhibited an efficiency of 3.9\% when a $25-\mathrm{nm}$ layer of PCBM was used. The efficiency of these devices was increased several-fold over a few years by optimization of perovskite grain formation and fullerene deposition. An appropriate choice of fullerene derivative has also become an important issue to be studied. Liang et al. systematically studied the incorporation of $\mathrm{IC}_{60} \mathrm{BA}, \mathrm{PC}_{60} \mathrm{BM}$, and $\mathrm{C}_{60}$ into a $\mathrm{MAPbI}_{3}$-based planar heterojunction SC [93]. They showed that the electron mobility of the fullerene layer is in direct correlation with device performance, indicating the importance of superior electron transfer efficiency. This observation contrasted with the highest efficiency of the PBCM-based device developed by Jeng et al. [7]. To resolve this contradiction, Zhang et al. fabricated a series of devices with $\mathrm{C}_{60}$, $\mathrm{C}_{70}, \mathrm{PC}_{60} \mathrm{BM}$, and $\mathrm{PC}_{70} \mathrm{BM}$, as depicted in Fig. 16 [94]. $\mathrm{PC}_{60} \mathrm{BM}$ and $\mathrm{PC}_{70} \mathrm{BM}$ were spin-coated on top of a $\mathrm{MAPbI}_{3-\mathrm{x}} \mathrm{Cl}_{\mathrm{x}}$ perovskite layer, while $\mathrm{C}_{60}$ and $\mathrm{C}_{70}$ were deposited by vacuum evaporation. It was observed that functionalized fullerenes exhibit superior efficiency to their pristine counterparts. It was speculated that solution-processed fullerenes were more suitable for perovskite passivation and ion migration blocking. They also provide adequate electron extraction and transfer.

It was also noticed that the choice of fullerene influences $\mathrm{V}_{\mathrm{OC}}$. The use of ICBA itself did not lead to the highest PCE [7,93], but the situation changes when an additional fullerene layer is deposited onto $\mathrm{IC}_{60} \mathrm{BA}$. Wang et al. showed that the formation of a double fullerene layer is especially beneficial when $\mathrm{C}_{60}$ is deposited on top of an $\mathrm{IC}_{60} \mathrm{BA}$ layer [95]. It was proposed that tiny fullerene molecules can fill the space between grain boundaries. Acting in this manner, they can effectively passivate trap states at both the perovskite surface and boundaries. Penetration of fullerenes through the active layer pinholes was considered to produce a Schottky junction between the fullerene and 
Table 3

Incorporation of graphene derivatives into HTL of PSCs.

\begin{tabular}{|c|c|c|c|c|c|c|c|c|}
\hline Material & Location & Structure & $\begin{array}{l}\text { PCE (\%) / Jsc (mA/ } \\
\left.\mathrm{cm}^{2}\right) / \operatorname{Voc}(\mathrm{V}) / \mathrm{FF} \\
(\%)\end{array}$ & $\uparrow \mathrm{PCE}$ & $\uparrow$ Stability & Improvements & Year & Ref \\
\hline GO & $\begin{array}{l}\text { Between active and } \\
\text { Spiro-OMeTAD }\end{array}$ & $\begin{array}{l}\mathrm{FTO} / \mathrm{TiO}_{2} / \mathrm{Act} / \\
\mathrm{Gr} / \mathrm{SO} / \mathrm{Au}\end{array}$ & $\begin{array}{l}15.1 / 20.2 / 1.04 / \\
73\end{array}$ & + & $\mathrm{n} / \mathrm{i}$ & $\begin{array}{l}\text { Improved wettability before HTL deposition; } \\
\text { improved current, voltage, and FF }\end{array}$ & 2014 & [83] \\
\hline rGO-4FPN & $\begin{array}{l}\text { Between active and } \\
\text { Spiro-OMeTAD }\end{array}$ & $\begin{array}{l}\mathrm{FTO} / \mathrm{TiO}_{2} / \mathrm{Act} / \\
\mathrm{Gr} / \mathrm{SO} / \mathrm{Au}\end{array}$ & $\begin{array}{l}18.7521 .5 / 1.11 / \\
78.6\end{array}$ & + & $\mathrm{n} / \mathrm{i}$ & $\begin{array}{l}\text { Improved } \mathrm{V}_{\mathrm{oc}} \text { due to passivation of the under- } \\
\text { coordinated } \mathrm{Pb} \text { ion traps }\end{array}$ & 2017 & [84] \\
\hline rGO & $\begin{array}{l}\text { Between active and } \\
\text { dopant-free Spiro- } \\
\text { OMeTAD }\end{array}$ & $\begin{array}{l}\mathrm{FTO} / \mathrm{TiO}_{2} / \mathrm{Act} / \\
\mathrm{Gr} / \mathrm{SO} / \mathrm{Au}\end{array}$ & $\begin{array}{l}10.6 / 16.73 / 0.91 \\
/ 61\end{array}$ & $+/-$ & + & Enhanced stability & 2015 & [85] \\
\hline NGs & $\begin{array}{l}\text { Between active and } \\
\text { dopant-free Spiro- } \\
\text { OMeTAD }\end{array}$ & $\begin{array}{l}\mathrm{FTO} / \mathrm{TiO}_{2} / \mathrm{Act} / \\
\mathrm{Gr} / \mathrm{SO} / \mathrm{Au}\end{array}$ & $\begin{array}{l}14.6 / 23.6 / 0.94 / \\
65.8\end{array}$ & + & $\mathrm{n} / \mathrm{i}$ & $\begin{array}{l}\text { Perovskite trap state reduction; improved hole } \\
\text { extraction and transfer }\end{array}$ & 2016 & [86] \\
\hline $\begin{array}{l}\text { TSHBC }+\mathrm{Gr} \\
\text { sheets }\end{array}$ & HTL & $\begin{array}{l}\mathrm{FTO} / \mathrm{TiO}_{2} / \mathrm{Act} / \\
\mathrm{Gr} / \mathrm{Au}\end{array}$ & $\begin{array}{l}14.02 / 21.91 / \\
0.97 / 66\end{array}$ & - & + & Enhanced stability & 2015 & [87] \\
\hline rGO & HTL & $\begin{array}{l}\mathrm{FTO} / \mathrm{TiO}_{2} / \text { Act/ } \\
\mathrm{Gr} / \mathrm{Au}\end{array}$ & $\begin{array}{l}6.62 / 11.5 / 0.95 / \\
60.5\end{array}$ & - & + & Enhanced stability & 2016 & [88] \\
\hline GO & $\begin{array}{l}\text { Between ITO and } \\
\text { PEDOT:PSS }\end{array}$ & $\begin{array}{l}\text { ITO/Gr/PP/Act/ } \\
\text { PCBM/LiF/Ag }\end{array}$ & $\begin{array}{l}9.74 / 15.75 / 0.84 \\
/ 73.6\end{array}$ & + & + & $\begin{array}{l}\text { Decreased series resistance and increased shunt } \\
\text { resistance; environmental stability }\end{array}$ & 2015 & [89] \\
\hline $\mathrm{AuCl}_{3}-\mathrm{Gr}$ & $\begin{array}{l}\text { Between ITO and } \\
\text { PEDOT:PSS }\end{array}$ & $\begin{array}{l}\mathrm{ITO} / \mathrm{Gr} / \mathrm{PP} / \mathrm{Act} / \\
\mathrm{PCBM} / \mathrm{BCP} / \mathrm{Al}\end{array}$ & $\begin{array}{l}15.9 / 20.59 / 1.0 / \\
77.2\end{array}$ & + & + & Enhanced performance; enhanced stability & 2018 & [60] \\
\hline $\mathrm{GO}: \mathrm{NH}_{3}$ & $\begin{array}{l}\text { Between PEDOT:PSS } \\
\text { and active }\end{array}$ & $\begin{array}{l}\text { ITO/PP/Gr/Act/ } \\
\text { PCBM/sBphen/ } \\
\text { Ag }\end{array}$ & $\begin{array}{l}16.11 / 22.06 / \\
1.03 / 71\end{array}$ & + & + & $\begin{array}{l}\text { Improved active layer structure; better matched } \\
\text { energy-level-alignment at the perovskite interface; } \\
\text { enhanced stability }\end{array}$ & 2016 & [68] \\
\hline AgOTf-GO & $\begin{array}{l}\text { Blend with PEDOT: } \\
\text { PSS }\end{array}$ & $\begin{array}{l}\text { ITO/PP-Gr/Act/ } \\
\text { PCBM/Au }\end{array}$ & $\begin{array}{l}11.9 / 19.18 / 0.88 \\
/ 70.5\end{array}$ & + & $\mathrm{n} / \mathrm{i}$ & Improved photovoltaic characteristics & 2015 & [58] \\
\hline GO & HTL & $\begin{array}{l}\text { ITO/Gr/Act/ } \\
\mathrm{PCBM} / \mathrm{ZnO} / \mathrm{Al}\end{array}$ & $\begin{array}{l}12.4 / 17.46 / 1.0 / \\
71\end{array}$ & - & $\mathrm{n} / \mathrm{i}$ & Improved perovskite morphology & 2014 & [90] \\
\hline rGO & HTL & $\begin{array}{l}\text { ITO/Gr/Act/ } \\
\text { PCBM/BCP/Ag }\end{array}$ & $\begin{array}{l}10.8 / 15.4 / 0.98 / \\
71.6\end{array}$ & + & + & $\begin{array}{l}\text { Improved performance; better perovskite } \\
\text { crystallinity; improved stability }\end{array}$ & 2015 & [91] \\
\hline $\mathrm{GO}, \mathrm{rGO}$ & HTL & $\begin{array}{l}\text { ITO/Gr/Act/ } \\
\mathrm{PCBM} / \mathrm{Ag}\end{array}$ & $\begin{array}{l}16.4 / 22.1 / 0.96 / \\
77\end{array}$ & + & $\mathrm{n} / \mathrm{i}$ & $\begin{array}{l}\text { Superior efficiency; balance between hole } \\
\text { extraction and transfer }\end{array}$ & 2018 & [92] \\
\hline
\end{tabular}


Fig. 16. The device structure (a) and its energy diagram (b) when different fullerene derivatives are used as an ETL [94].

hole-transporting layer, which is sensitive to fullerene LUMO and, consequently, fullerene type. This hypothesis was further confirmed by preventing possible contact between the hole- and electron-transporting layers [31].

Further improvements in the fullerene-based electron-transporting layer can be achieved by fullerene doping and functionalization, enhancing charge extraction and morphology [96]. Lin et al. used a small amount of the block copolymer to improve the morphology of the ETL [97]. They found that interaction between $\mathrm{PC}_{60} \mathrm{BM}$ and the polymer leads to the formation of smaller clusters which can further aggregate into a dendritic-like structure. The improved morphology of this ETL led to a higher fill factor and a 43\% enhancement in the PCE. Zwitterionic fulleropyrrolidines $\left(\mathrm{C}_{60}-\mathrm{SB}\right)$ have been developed as an additional interfacial layer for organic photovoltaics [98]. The main purpose of this layer is to eliminate the trade-off between cathode work function and its oxidation stability. Duzhko et al. later showed that additional doping of $\mathrm{C}_{60}$-BM by tetra-n-butyl ammonium iodide (TBAI) allows further increases in the efficiency of both organic and perovskite solar cells [99].

Effective passivation of the trap states creates an additional desirable effect. The normal planar heterojunction architecture with a perovskite/ fullerene junction allowed the demonstration of a hysteresis-free PSC for the first time [95]. Indeed, incorporation of fullerenes onto perovskite grains and between grain boundaries allowed both a reduction in charge trap density and prevented ion migration, which is considered to be responsible for photocurrent hysteresis $[31,100]$. However, the exact mechanism of photocurrent hysteresis suppression is still a topic of debate. Liu et al. have recently shown that evaporation of an ultrathin $(\sim 1 \mathrm{~nm})$ layer of pristine $C_{60}$ allows effective electron extraction and hysteresis suppression [101]. The authors concluded that the hysteresis phenomenon should be ascribed to space charge accumulation at the 
interface. A thin $\mathrm{C}_{60}$ layer was able to enhance carrier extraction and, hence, to block the main mechanism for photocurrent hysteresis.

\subsection{Normal architecture}

Wojciechowski et al. pointed out that slow electron transfer from the perovskite to the $\mathrm{TiO}_{2}$ can seriously limit device performance [40]. To address this problem, a monolayer of self-assembled fullerene $\left(\mathrm{C}_{60}\right.$-SAM) was formed on top of the compact $\mathrm{TiO}_{2}$ layer. PL decay measurements showed that the combination of $\mathrm{TiO}_{2}$ and $\mathrm{C}_{60}-\mathrm{SAM}$ acts as a much more effective quencher for the perovskite film. The drastically improved ETL enabled a change in the device operation mode, making it an n-i-p heterojunction. Importantly, a dramatic increase in device efficiency was supported by reduced photocurrent hysteresis. In later work, fullerene derivatives have been used in tandem with different acceptor materials, such as $\mathrm{ZnO}$ [102], $\mathrm{SnO}_{2}$ [103], and $\mathrm{WO}_{\mathrm{x}}$ [104] (see Fig. 17).

After the discovery of the superior role of fullerenes for electron extraction in a normal planar heterojunction architecture, it was necessary to address technological issues. Snaith's group applied a crosslinking technique to eliminate partial dissolution of a thin organic layer during perovskite film formation [105]. These devices, with cross-linked fullerene derivatives, became the first with a sole fullerene-based ETL for this type of PSC. This advance motivated a further search for an optimal strategy for the formation of fullerene-based ETLs. Topolovsek et al. used a self-assembled layer of siloxane functionalized fullerene on top of the FTO transparent electrode. The devices demonstrated a 15\% PCE and stability under UV light exposure [106]. Collavini et al. proposed a fullerene saturation approach to form either a $\mathrm{C}_{60}$ or $\mathrm{C}_{70}$ electron transporting layer on top of the FTO electrode [107]. To prevent washing of the fullerene ETL during perovskite deposition, pre-deposited $\mathrm{C}_{60}$ and $\mathrm{C}_{70}$ transporting layers were exposed to DMF fullerene-saturated solution. These films demonstrated improved morphology and better photovoltaic characteristics. Wet-processing of the fullerene-based ETL has an undoubted technological advantage, however, it has some restrictions in terms of photovoltaic characteristics. Lin et al. have shown that the lower efficiency obtained for "wet" fullerene-based ETLs in comparison to those obtained by thermal evaporation can be ascribed to undesired crystallinity and residual solvent [108]. To solve the problem, the authors used a mixture of $\mathrm{C}_{60}$ and $\mathrm{C}_{70}$, which is not as prone to crystallization. Additional enhancements of fill factor and $V_{O C}$ were achieved by vacuum-drying of the ETL film

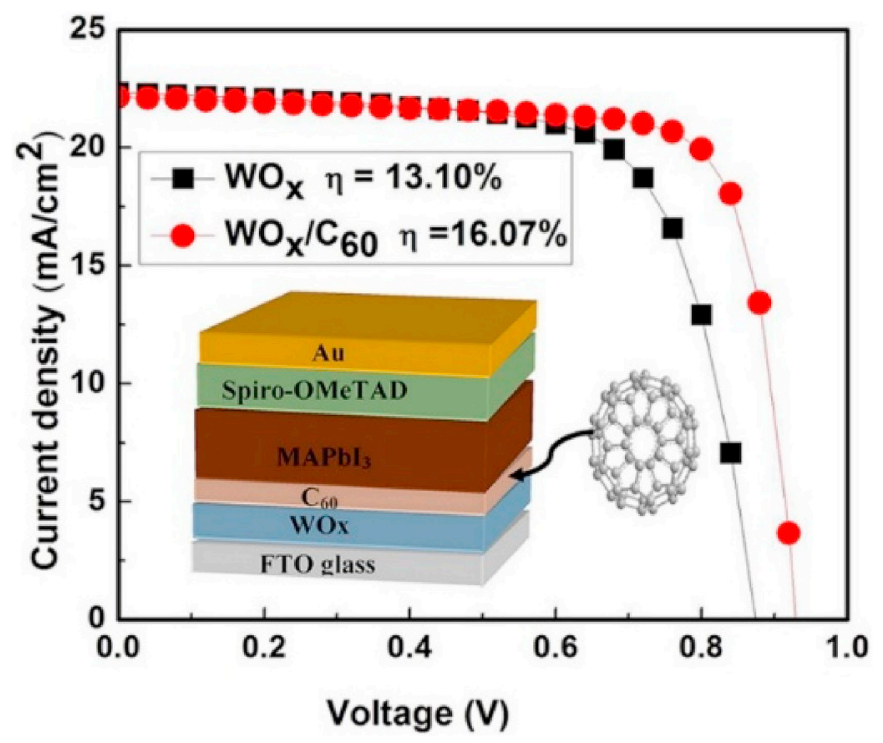

Fig. 17. The use of fullerene derivatives for optimization of electron extraction in normal planar heterojunction PSCs [104]. before perovskite layer fabrication.

\section{Carbon nanotubes in PSCs}

\subsection{Carbon nanotubes properties}

A carbon nanotube (CNT) is a cylindrical-shaped carbon allotrope which can be imagined as one (single-wall CNT) or several (multi-wall $\mathrm{CNT}$ ) rolled graphene sheets. These sheets can be rolled at specific angles that are determined by chiral indices. Depending on the chiral index, CNTs can exhibit either metallic or semiconducting properties. Only semiconducting CNTs can be used as a charge transporting layer since metallic CNTs usually form a Schottky barrier between the semiconductor and m-CNTs [109]. High carrier mobility and long charge carrier lifetimes, mechanical and chemical stability make CNTs an attractive candidate to replace unstable, organic, hole-transporting materials in PSCs. It has been shown that CNTs can provide faster hole extraction than spiro-OMeTAD and longer hole lifetimes [110]. Currently, CNTs serve multiple functions, acting as both hole extractor and electrode, eliminating the use of highly-expensive noble metal cathodes. CNTs can be improved by coating them with polymers for better morphology, or by chemical doping, which is often used to reduce $\mathrm{CNT}$ resistance and enhance carrier transport.

\subsection{Carbon nanotubes in PSCs}

Different types of HTL with CNTs are listed in Table 4. In the simplest approach, CNTs can be used as an additive to well-known hole-transporting layers or p-type organic semiconductors. Cai et al. demonstrated that CNTs facilitate better morphology and crystallinity of the P3HT (poly(3-hexylthiophène)) hole-transporting layer [111]. In this way, over one order of magnitude higher conductivity was achieved by the addition of $1-2 \mathrm{wt} \%$ of CNTs to P3HT. Clearly, given the sensitivity of the conductivity to CNT concentration, a careful adjustment of the CNT concentration is required. The widely used Spiro-OMeTAD requires additional doping to improve its conductivity. Since these additives are known to induce premature degradation of PSCs due to their hygroscopicity, CNTs have been considered as chemically-stable replacements for Li-TFSI and other dopants. Miletić et al. utilized two differently functionalized single-wall CNTs (SWNTs) as a dopant for spiro-OMeTAD [112]. This hybrid HTL gave a slightly poorer performance but enhanced degradation resistivity. Wang et al. used multi-walled CNTs (MWNTs) in a similar manner [113]. They proposed using an acid-treatment that facilitated better MWNT dispersibility due to the enhanced $\pi-\pi$ interaction with spiro-OMeTAD. In some cases, it was found that the prior deposition of a thin doped spiro-OMeTAD layer before hybrid Spiro-OMeTAD/CNTs composite deposition protects the devices from back-electron transfer. This occurs where the perovskite and CNTs are in contact [114].

Another method of combining CNTs and spiro-OMeTAD is to transfer the CNTs first and then to deposit spiro-OMeTAD. In these devices, the CNTs usually act as both a hole-transporting material and a selective contact. Wang et al. produced a flexible solar cell using Ti-foil and CNTs

Table 4

Different types of HTL with CNTs.

\begin{tabular}{ll}
\hline Structure & References \\
\hline P3HT-CNTs blend & {$[111]$} \\
Spiro-CNTs blend & {$[112,113]$} \\
Spiro/spiro-CNTs blend & {$[114]$} \\
CNTs transferred/spiro & {$[115-117]$} \\
CNT spin-coated/spiro & {$[118]$} \\
Wrapped-CNTs/spiro & {$[119,120]$} \\
Wrapped-CNTs/PMMA & {$[121]$} \\
GO-CNTs/PMMA & {$[122]$} \\
Graphene-CNTs & {$[29]$} \\
\hline
\end{tabular}


as electrodes [115]. Here, CNT film was first assembled on nickel foil and then transferred to the perovskite layer. Subsequently, spiro-OMeTAD was spin-coated on top of the CNT layer. They achieved a PCE of $8.31 \%$ which slightly decreased after 100 bending cycles. Aitola et al. fabricated a highly-efficient conventional solid-state PSC with a hybrid HTL/electrode [116]. This cell exhibited a PCE of 15.5\%, lower than that achieved with a conventional spiro-OMeTAD/Au device (18.8\%). However, using carbon materials can dramatically reduce manufacturing costs, avoiding the use of noble metals. Later, the same group performed a stability test for these devices [117]. As in the previous study, CNTs were first transferred to the perovskite absorber layer. A few drops of spiro-OMeTAD were then drop-casted. Despite the use of dopants for the spiro-OMeTAD layer, metal-free devices demonstrated superior stability: the lifetime at $60{ }^{\circ} \mathrm{C}$ in a nitrogen atmosphere was estimated to be $580 \mathrm{~h}$.

An elegant approach that eliminates the necessity of using a technologically unattractive CNTs transfer process has been recently proposed by Tiong et al. [118]. SWNTs were functionalized by nitric acid and octadecylamine, as depicted in Fig. 18, and then dissolved in 1, 2-dichlorobenzene. The perovskite active layer was spin-coated by a two-step process and then a SWNT solution was added $10 \mathrm{~s}$ before the end of the process. After heating and annealing, doped spiro-OMeTAD was spin-coated and the device was completed by evaporation of an $\mathrm{Au}$ electrode. In this device, CNTs were found to have multiple functions. Beside holes extraction and transfer, the CNTs influenced the formation of perovskite grains. The increased grain size and reduction of grain boundaries allowed the device efficiency to increase and reduced $\mathrm{J}-\mathrm{V}$ hysteresis. Despite the use of dopants, the device retained $81 \%$ of its initial efficiency after 45 days of storage at ambient environment and $60-90 \%$ humidity.

The high aspect ratio and strong van der Waals interactions make CNTs prone to aggregation. The necessity for careful control of morphology may hinder their technological application. To eliminate this problem, CNTs can be wrapped using different polymers. Typically, p-type conjugated polymers are used, and the $\pi-\pi$ interaction is considered to be a driving force for polymer wrapping. In one seminal study, Habisreutinger et al. deposited P3HT-wrapped SWNTs onto a perovskite layer prior to spin-coating a pristine spiro-OMeTAD layer [119]. They showed that this double-layer structure gives a higher performance than a mixture of spiro-OMeTAD and CNTs. The drawbacks of p-type conjugated polymers are their high price and instability. Mazzotta et al. have recently shown that an inexpensive non-conjugated polymer, ethylene vinyl acetate (EVA), can be also used for functionalization of both single- and multi-walled CNTs [120]. Despite the insulating nature of the pristine polymer, hybrid films fabricated from EVA-wrapped CNTs show a very high conductivity. This approach enables the fabrication of highly efficient devices, up to $17.1 \%$, and reduces manufacturing costs by eliminating the use of very expensive conjugated polymers. In fact, expensive and unstable spiro-OMeTAD can also be replaced by a cheap insulating polymer, as first demonstrated by Snaith's group [121]. An insulating polymer matrix still allows efficient charge collection, but also provides additional structural features and stability in humid ambients. The authors showed that a hybrid HTL based on P3HT/SWNTs-PMMA (Poly(methyl methacrylate)) demonstrates superior stability as compared to conventionally used Spiro-OMeTAD, P3HT, and PTAA (Fig. 19c). The stability of the efficiency for samples with a P3HT/SWNTs-PMMA HTL is improved after thermal treatment. These samples maintained their efficiency after $60 \mathrm{~s}$ under direct water flow (Fig. 19d).

An interesting concept is to combine the exceptional hole extraction and electron blocking of CNTs and GO. Wang et al. found that a bicomponent hole transporting layer consisting of SWNTs and GO doubles the efficiency as compared to a cell with CNTs only [122]. Here, the additional use of an insulating PMMA matrix also improved the $\mathrm{V}_{\mathrm{OC}}$ and fill factor, yielding a PCE of over 10\%. Importantly, the device demonstrated superior stability in atmospheric conditions. Zhang and co-workers utilized a combination of graphene flakes and acid-functionalized MWNTs as an HTL in an inverted planar PSC [29]. Dispersion of the graphene-CNTs was obtained via ultrasonication in $\mathrm{N}$, $\mathrm{N}$-dimethylformamide followed by spin-coating on an ITO substrate. After perovskite layer formation, the PCBM was spin-coated and the Ag electrode was thermally evaporated. The device demonstrated an average PCE of $14.8 \%$, higher than that obtained from a device with a more convenient PEDOT:PSS HTL.

\section{Graphene quantum dots and carbon dots in PSCs}

\subsection{Graphene quantum dots}

Graphene quantum dots (GQDs) are a very unusual member of the carbon family. GQDs usually consist of 1-2 atomic layers of graphene, with a lateral dimension of less than $10 \mathrm{~nm}$. GQDs can be prepared using both bottom-up and top-down strategies, with advantages and disadvantages to both approaches. An important distinguishing characteristic of GQDs from other carbon-family members is their bandgap sizedependence due to quantum confinement effects. Due to the small size and high surface area, the physical and chemical properties of GQDs are extremely sensitive to doping, functionalization and defects. Heteroatom doping is a powerful tool for tuning their properties. Tuning can be performed either during synthesis or via post-synthetic treatment. Engineering of the GQD properties allows their wide application in photovoltaics. They are already used as part of the active and ancillary layers in hybrid, silicon and perovskite photovoltaics [123].

Zhu et al. synthesized 5-10 nm GQDs and deposited an ultrathin layer between mesoporous $\mathrm{TiO}_{2}$ and perovskite in a normal mesosuperstructured PSC [45]. With an optimal GQD solution concentration of $0.5 \mathrm{mg} / \mathrm{ml}$, the devices demonstrated an average PCE of 9.8\%, $1.2 \%$ higher than those without GQDs. The improved PCE was attributed mainly to photocurrent enhancement due to improved electron extraction. Shen et al. has recently utilized the same PSC architecture and proposed a method for $\mathrm{TiO}_{2}$ decoration [41]. A schematic diagram of their device is shown in Fig. 20. In order to decorate the $\mathrm{TiO}_{2}$ film with GQDs, the authors soaked the mesoporous film in a GQD solution, followed by spin-coating and drying at $100{ }^{\circ} \mathrm{C}$. The decoration led to a

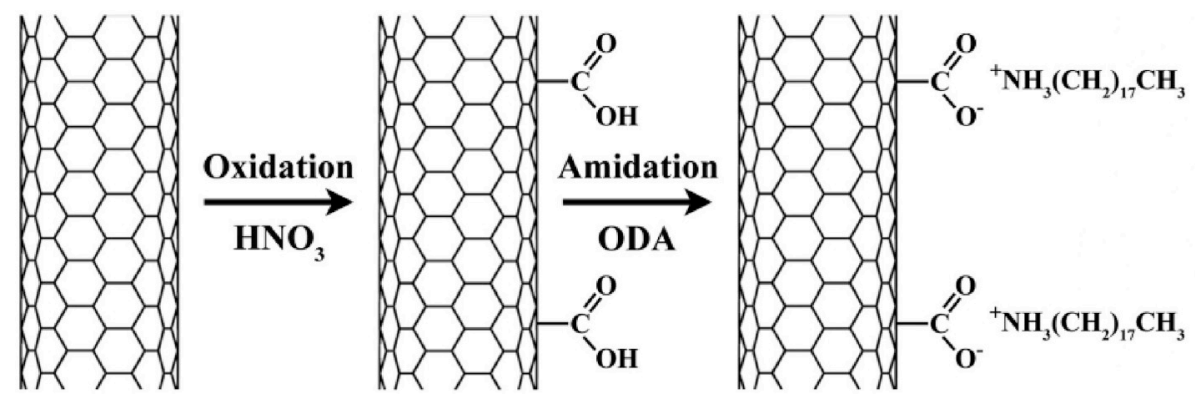

Fig. 18. Double functionalization of SWCTs [118]. 


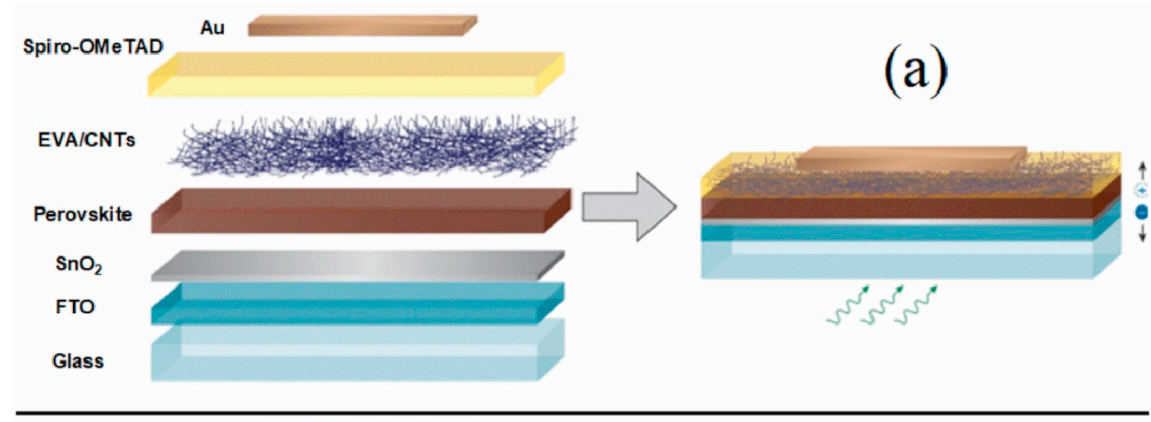

$\mathrm{Ag}$

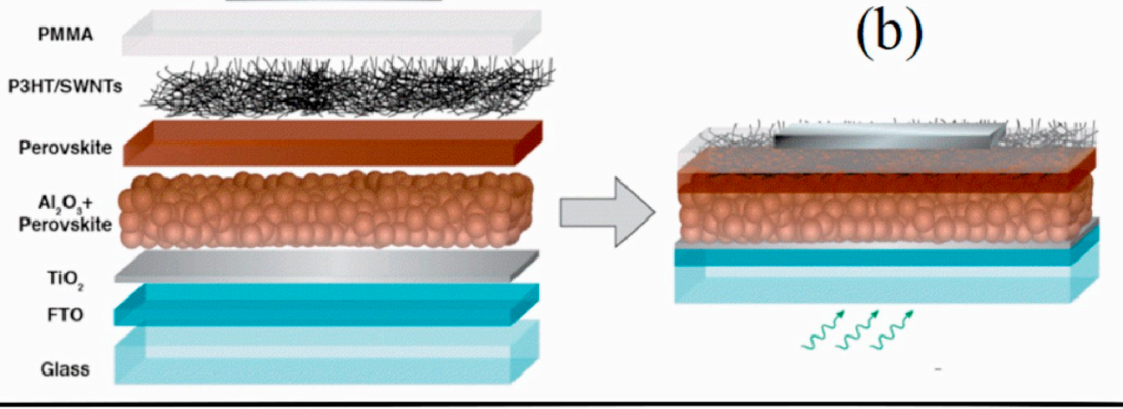

(c)

$0 \mathrm{~h} \quad 24 \mathrm{~h}$

$48 \mathrm{~h}$

$72 \mathrm{~h}$

$96 \mathrm{~h}$

Li-spiro-OMeTAD
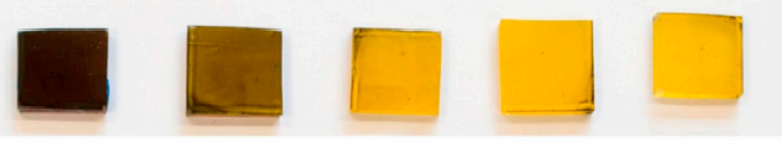

P3HT

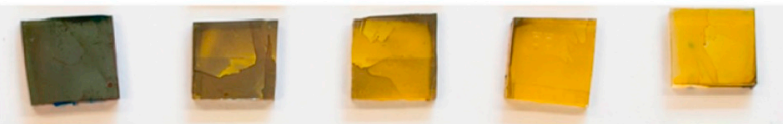

PTAA


PMMA


\section{P3HT/SWNT-PMMA}


(d)


Fig. 19. Wrapping the CNTs with insulating (a) [120] and p-type conjugated (b) [121] polymer and capping by conductive (a) and insulating (b) polymer. Thermal (c) and moisture (d) stability of the PSCs with a hybrid P3HT/SWNTs-PMMA HTL [121]. 



Fig. 20. Schematic diagram of the device with GQD-decorated mesoscopic $\mathrm{TiO}_{2}$ ETL [41].

reduction of serial resistance, better electron extraction and higher current, boosting the efficiency from $18.57 \%$ to $20.45 \%$.

GQDs have been shown to improve electron extraction in different
ETLs for planar normal PSCs. Yang and co-workers used low GQD doping concentrations to improve the electron extraction and conductivity of a PCBM ETL [124]. 0-1 wt\% of GQDs were stirred in a PCBM


Fig. 21. Use of quantum-confinement in GQDs for adjusting their energy levels in the ETL [129]. 
solution and then spin-coated on to ITO glass. The authors observed that this low concentration of GQDs leads to better electron extraction, higher electron mobility and suppressed hysteresis. The PCE achieved increased from $14.68 \%$ to $17.56 \%$ and exhibited very good stability in air for 30 days. Several studies were concerned with blending GQDs with $\mathrm{SnO}_{2}$. To modify this ETL, a small concentration of GQDs can be mixed with a $\mathrm{SnCl}_{2} \cdot 2 \mathrm{H}_{2} \mathrm{O}$ precursor [125] or with tin oxide nanoparticles [126]. 0.5-1 wt \% of GQDs in a $\mathrm{SnCl}_{2} \cdot 2 \mathrm{H}_{2} \mathrm{O}$ precursor created a marked improvement in the ETL. A reduction in the work function and an improvement in conductivity were ascribed to filling the trap states and an elevated electron density in the conduction band. As a result, the device was hysteresis free and had a PCE of 20.31\% [125]. Zhou et al. mixed GQDs with tin oxide nanoparticles to obtain an ETL for conventional and flexible devices [126]. Adding the GQDs led to increased photocurrent and voltage, and reduced hysteresis. A thorough optimization of the GQDs concentration gave a peak PCE of $19.6 \%$ for the rigid substrate and $17.7 \%$ for the flexible one, which retained $91 \%$ of its original efficiency after 500 bending cycles.

Various methods exist for tuning of GQD physical properties. The electronic structure of GQDs can be tuned by varying their size, due to the quantum confinement effect which arises from the change of the $\mathrm{sp}^{2}$ domains and the $\pi^{*}-\pi$ gap $[127,128]$. Ryu et al. investigated the effect of GQD size on the performance of normal planar PSCs [129]. 7, 10, and $14 \mathrm{~nm}$ GQDs were prepared by chemical oxidation and cutting from carbon fibers, and their size was tuned by varying the oxidation temperature. Different-sized GQDs possess size-dependent optical properties, as shown in Fig. 21. For device fabrication, an aqueous solution of GQDs was spin-coated on top of a compact $\mathrm{TiO}_{2}$ layer. For all GQD sizes, an improvement of the photovoltaic characteristics was observed. GQDs improved the interface between the $\mathrm{TiO}_{2}$ and perovskite layers, which optimized electron extraction, decreased serial resistance, improved perovskite quality, and reduced hysteresis. The PCE of the devices increases with GQD size, demonstrating a better match of their energy levels. This observation is supported by steady-state and transient PL spectroscopy of perovskite deposited on GQDs of different sizes. The authors observed both quenching of PL intensity and a reduction in PL lifetime. The PCE reduction closely matches the reduction in PL lifetime, indicating that the enhancement of the device performance is caused by a GQDs size-dependent improvement in the ETL/perovskite interface.

Doping is another versatile approach to adjust GQDs properties. Tetsuka et al. demonstrated the design of GQDs which allows continuous tuning of their energy levels as shown in Fig. 22 [130]. Nucleophilic substitution and the dehydration reaction of amine moieties were used to obtain a set of nitrogen-functionalized GQDs. $\mathrm{NH}_{2^{-}}$, OPD- (o-phenylenediamine), and DAN-GQDs (diaminonaphthalene) have their LUMO level close to $4.0 \mathrm{eV}$ and have been tested as an electron transporting interlayer. In their devices, $\mathrm{TiO}_{2}$ was covered by a thin layer of GQDs by spin-coating from a DMF dispersion and dried at $100^{\circ} \mathrm{C}$ for 10 min. Ultrafast spectroscopy showed accelerated electron extraction. This allowed an improvement of the PCE of the fabricated devices from 6.77 to $7.79 \%$.

\subsection{Carbon dots}

Carbon dots (CDs) are a rather wide class of carbon material. CDs are mostly spherical, with a characteristic size of less than $10 \mathrm{~nm}$. The structure of CDs may vary, depending on the synthesis method, combining crystalline and amorphous components [131]. Their poorer crystallinity and different shape distinguish them from GQDs, which, in principle, can be considered as a sub-type of CDs [131,132]. For both CDs and GQDs, functionalization with complex groups or heteroatom doping may play a key role in the determination of their physical properties [133]. In CDs, the functionalization layer is usually disordered, can have a thickness of few nanometers, and must be considered as an entire structure with a carbon core [131].

CDs have been utilized as either an HTL or an ETL in normal and inverted PSCs. Jin et al. immersed a substrate with $\mathrm{FTO} / \mathrm{c}-\mathrm{TiO}_{2} / \mathrm{m}-\mathrm{TiO}_{2}$ into a CD solution to make an improved ETL in a mesoporous PSC [134]. A schematic of their device is shown in Fig. 23. They showed that embedding CDs facilitates electron transport, increasing the PCE to $16.4 \%$. CDs exhibit strong absorption in the UV spectral region and can additionally serve as a protective filter. Indeed, the authors mentioned the improved device stability under full sunlight illumination. Li et al. used a solution-preceded composite of $\mathrm{TiO}_{2}$ and $\mathrm{CDs}$ to fabricate an effective ETL for a planar PSC by one-step deposition [135]. The CD concentration played an important role, at $10 \mathrm{wt} \%$ both the open circuit voltage and short-circuit current improved, and the enhanced PCE of their best device reached a value of $18.9 \%$. The modified ETL demonstrated better electron extraction, as confirmed by time-resolved PL and TAS analysis (Fig. 24). The PL lifetime reduced from 4.64 to $2.64 \mathrm{~ns}$ for $\mathrm{MAPbI}_{3-\mathrm{x}} \mathrm{Cl}_{\mathrm{x}}$ films on $\mathrm{TiO}_{2}$ and $\mathrm{CDs} / \mathrm{TiO}_{2}$ ETLs, respectively. Nanosecond TAS measurements revealed differences in both photoinduced absorption and photoinduced bleaching peaks for the two samples. The photobleaching peak was attributed to relaxation of the excited state and free carrier recombination. The authors pointed out that the longer time constant, observed for the CD-modified samples, allows additional
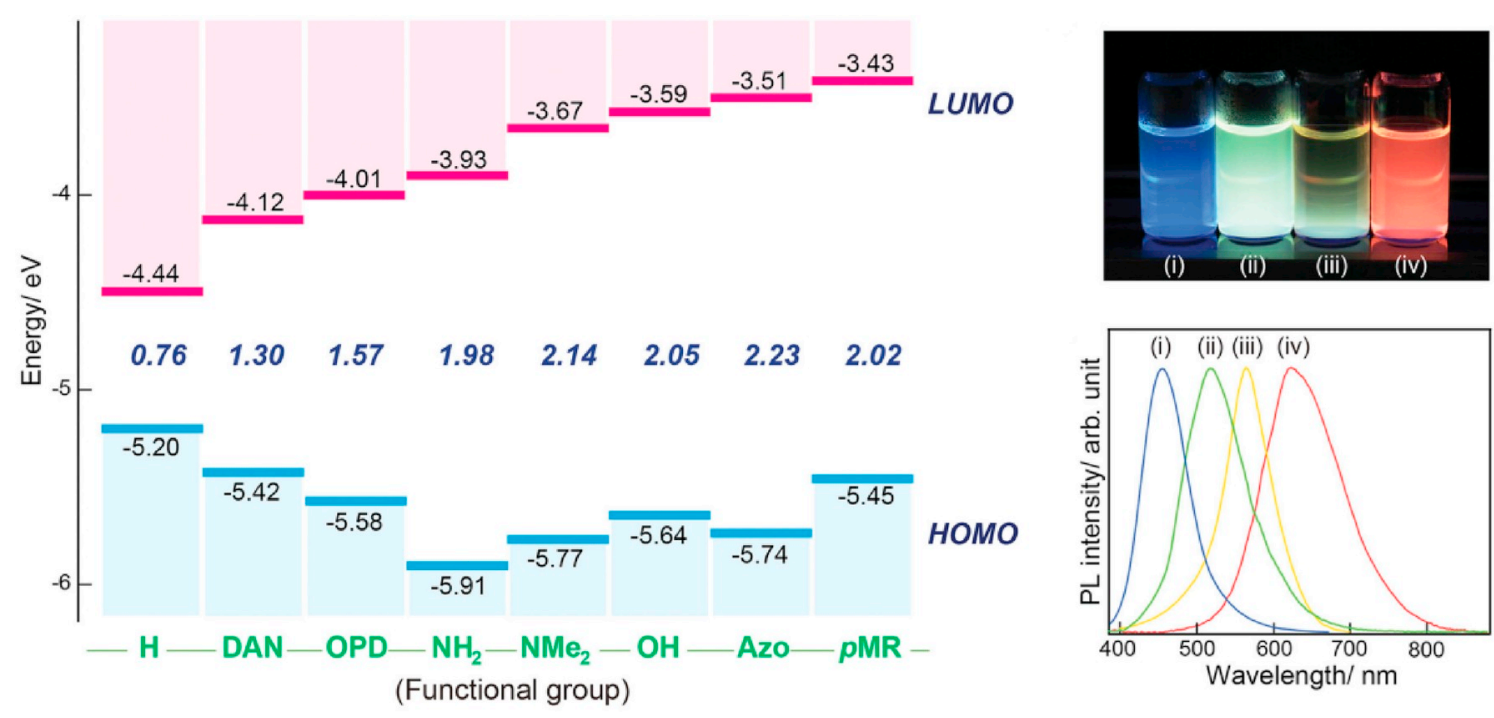

Fig. 22. Nitrogen doping allows continuous tuning of the GQDs energy levels position [130]. 


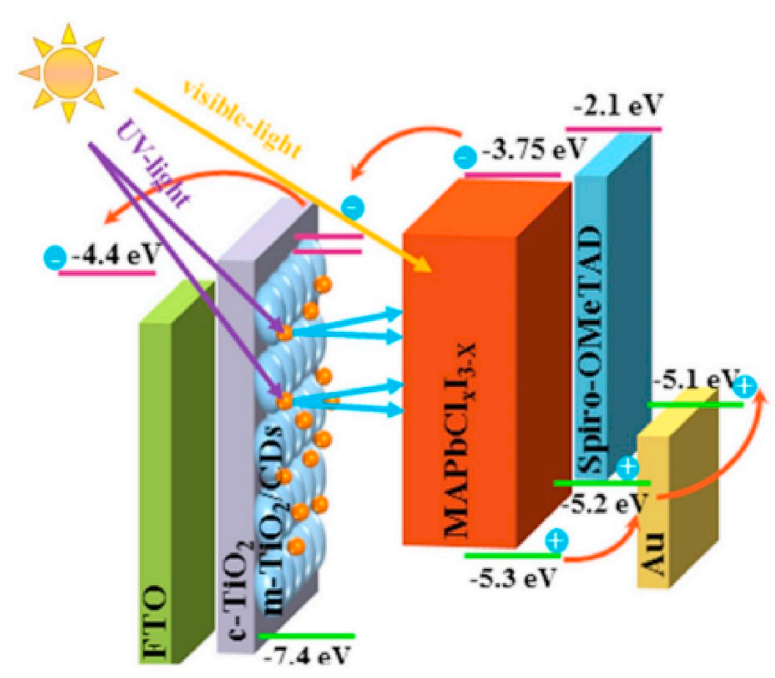

Fig. 23. An FTO substrate with compact and mesoporous $\mathrm{TiO}_{2}$ was immersed in CDs solution to promote electron transport and block UV radiation [134].

time for the extraction of excited carriers.

Paula et al. compared the efficiency of CDs and doped spiro-OMeTAD as an HTL in a normal mesoscopic PSC [136]. CDs were spin-coated on perovskite film from an isopropanol solution, giving a 3.0\% PCE, much lower than that obtained with spiro-OMeTAD (8.06\%). A more effective way to produce a CD-based HTL for PSC was proposed by $\mathrm{Li}$ and co-workers, who used S,N co-doped CDs during PEDOT:PSS synthesis [137]. Since they used an inverted structure, optimizing the HTL allowed better contact with the perovskite absorber and reduced the interfacial trap state density. The PCE increased from 15.41 to $18.03 \%$ and the device also showed improved atmospheric and illumination stability. We should point out that both GQDs and CDs have been used in a mix with perovskite precursors to fill the grain boundaries, that is, however, not considered in this Review [138-140]. Some results obtained using GQDs and CDs are listed in Table 5.

\section{Conclusion and future outlooks}

In this Review, we summarize a versatile approach to using carbon nanomaterials as charge transporting layers in perovskite photovoltaics. As the interfacial layer, carbon nanoforms perform a multiplicity of roles including:
a) Electron/hole extraction and transfer
b) Control of perovskite grain morphology
c) Moisture protection
d) Current hysteresis suppression
e) Charge-selective electrode

The use of carbon nanomaterials in perovskite solar cells is attractive for many reasons. Firstly, numerous studies demonstrate an improvement in the photovoltaic characteristics of PSCs due to enhanced charge extraction and transfer. In many cases, carbon-based nanomaterials exhibit superior operating parameters to those obtained using standard polymeric materials. Secondly, many carbon nanomaterials allow straightforward and continuous tuning of their properties. This characteristic can be applied to precisely select the Fermi level position, solubility, morphology and other key characteristics for a better match with the perovskite layer and electrodes, to serve as both an electronand hole-transporting material. Thirdly, carbon nanomaterials offer the possibility of using low-cost and environmentally-friendly materials. Last, but not least, the impressive PSC stability obtained using carbon nanomaterials removes an important barrier to large scale commercial adoption.

Important issues remain. For instance, several useful approaches have been developed for tuning the Fermi level position in rGO and GO,


Fig. 24. PL and TAS analysis demonstrating enhanced performance of CD-modified ETL [135]. 
Table 5

Improvement of PCE of PSCs with GQDs and CDs.

\begin{tabular}{|c|c|c|c|c|c|c|}
\hline Material & Role & PSC type & Preparation & PCE improvement & Year & Ref. \\
\hline GQDs & ETL & Normal meso & $\begin{array}{l}\text { Ultrathin layer of GQDs deposited between perovskite and the mesoporous } \\
\text { titanium dioxide }\end{array}$ & from $8.81 \%$ to $10.15 \%$ & 2014 & [45] \\
\hline GQDs & ETL & Normal meso & $\begin{array}{l}\text { A DMF dispersion of Nitrogen-Functionalized GQDs was spin-coated on top of } \\
\text { the } \mathrm{TiO}_{2}\end{array}$ & From $6.77 \%$ to $7.79 \%$ & 2016 & [130] \\
\hline GQDs & ETL & Normal meso & $\begin{array}{l}\mathrm{mp}-\mathrm{TiO}_{2} \text { film was soaked with GQD solution for } 10 \mathrm{~s} \text { before spin coating. After } \\
\text { spin coating for } 20 \mathrm{~s} \text { at } 2000 \\
\text { r.p.m/min, the substrate was heated at } 100{ }^{\circ} \mathrm{C} \text { for } 30 \mathrm{~min} \text {. }\end{array}$ & From $18.57 \%$ to $20.45 \%$. & 2018 & [41] \\
\hline GQDs & ETL & $\begin{array}{l}\text { Normal } \\
\text { planar }\end{array}$ & Blend with PCBM & from $14.68 \%$ to $17.56 \%$ & 2017 & [124] \\
\hline GQDs & ETL & $\begin{array}{l}\text { Normal } \\
\text { planar }\end{array}$ & Blend with $\mathrm{SnCl}_{2} \cdot 2 \mathrm{H}_{2} \mathrm{O}$ precursor & From 17.91 to 20.31 & 2017 & [125] \\
\hline GQDs & ETL & $\begin{array}{l}\text { Normal } \\
\text { planar }\end{array}$ & Blend with tin oxide nanoparticles & $\begin{array}{l}\text { From } 16.7 \% \text { to } 19.6 \% \text { for rigid, } 17.7 \% \text { for } \\
\text { flexible }\end{array}$ & 2019 & [126] \\
\hline CDs & ETL & Normal meso & $\begin{array}{l}\mathrm{FTO} / \mathrm{c}-\mathrm{TiO}_{2} / \mathrm{m}-\mathrm{TiO}_{2} \text { were immersed in the } \mathrm{CDs} \text { solution and kept in the dark for } \\
\text { different times }\end{array}$ & From $14.61 \%$ to $16.40 \%$ & 2017 & [134] \\
\hline CDs & ETL & $\begin{array}{l}\text { Normal } \\
\text { planar }\end{array}$ & Blend with $\mathrm{TiO}_{2}$ & from $12.7 \%$ to $17.6 \%$ & 2017 & [135] \\
\hline CDs & HTL & Normal meso & Spin-coated on perovskite & $\begin{array}{l}\text { From } 0.71 \text { (no HTL) to } 3.00 ; 8.06 \text { with } \\
\text { spiro-OMeTAD }\end{array}$ & 2016 & [136] \\
\hline CDs & HTL & $\begin{array}{l}\text { Inverted } \\
\text { planar }\end{array}$ & S,N co-doped CNDs were used during PEDOT:PSS synthesis & From $15.41 \%$ to $18.03 \%$ & 2019 & [137] \\
\hline
\end{tabular}

allowing their use for hole- and electron-extraction, with a perfect match to the device energy diagram. Unfortunately, fabrication of high-quality thin films of these graphene derivatives is not straightforward. The CVD method cannot be applied for large-scale manufacturing. So GQDs and CDs enjoy a technological advantage, however, the methods available for tuning their properties are at present, immature technologically. Only fullerenes are effective for hysteresis reduction, with the exact mechanism still a matter of debate. Determination of the exact mechanism of hysteresis suppression will allow the use of other carbon nanomaterials in a controlled way to create stable and hysteresis-free devices. Similar considerations apply to the influence of various factors on the stability of PSCs in ambient conditions. While impressive preliminary results constitute an important step towards stable devices, it is only by discovery of the exact mechanisms of device degradation that we can hope to engineer carbon nanomaterials to counter this phenomenon. To summarize, several aspects of the behavior of these material systems need to be understood before carbon nanomaterials can be applied to perovskite photovoltaics.

Control of the interfaces within perovskite solar cells can lead to high-surface-area charge-separating junctions, bringing device performance closer to the theoretical limit. One possibility is to employ a group of carbon-based films as the recombination layer in multi-junction solar cells, providing a progression of work functions to allow matched hole and electron currents to meet and recombine. A perovskite solar cell could be integrated with infrared-bandgap semiconductors, such as $\mathrm{PbSe}$ or PbS quantum dots, to harvest a wider range of photons from the solar spectrum. With the aid of cheap, easily-synthesized, and stable carbon interface materials, the performance of solution-processed perovskite photovoltaics will continue to improve as their cost is reduced, ultimately allowing large scale commercialization.

\section{Acknowledgment}

This work was supported by the Russian Science Foundation (Agreement 18-13-00200). A.P.L. thanks the Ministry of Education of the Russian Federation for the financial support ((Goszadanie no. 16.8981.2017/8.9 and Scholarship of the President of the Russian Federation for young scientists and graduate students, SP-70.2018.1).

\section{References}

[1] Steirer KX, Schulz P, Teeter G, Stevanovic V, Yang M, Zhu K, et al. Defect tolerance in methylammonium lead triiodide perovskite. ACS Energy Lett 2016;1: 360-6.
[2] Dong Q, Fang Y, Shao Y, Mulligan P, Qiu J, Cao L, et al. Electron-hole diffusion lengths $>175 \mu \mathrm{m}$ in solution-grown $\mathrm{CH} 3 \mathrm{NH} 3 \mathrm{PbI} 3$ single crystals. Science 2015;347:967-70.

[3] Kojima A, Teshima K, Shirai Y, Miyasaka T. Organometal halide perovskites as visible-light sensitizers for photovoltaic cells. J Am Chem Soc 2009;131:6050-1.

[4] n.d, https://www.nrel.gov/pv/assets/pdfs/best-research-cell-efficiencies-19041 6.pdf. https://www.nrel.gov/pv/assets/pdfs/best-research-cell-efficiencies -190416.pdf.

[5] Lee MM, Teuscher J, Miyasaka T, Murakami TN, Snaith HJ. Efficient hybrid solar cells based on meso-superstructured organometal halide perovskites. Science 2012;338:643-7.

[6] Liu M, Johnston MB, Snaith HJ. Efficient planar heterojunction perovskite solar cells by vapour deposition. Nature 2013;501:395-8.

[7] Jeng J-Y, Chiang Y-F, Lee M-H, Peng S-R, Guo T-F, Chen P, et al. $\mathrm{CH}_{3} \mathrm{NH}_{3} \mathrm{PbI}_{3}$ perovskite/fullerene planar-heterojunction hybrid solar cells. Adv Mater 2013; 25:3727-32.

[8] Malinkiewicz O, Yella A, Lee YH, Espallargas GM, Graetzel M, Nazeeruddin MK, et al. Perovskite solar cells employing organic charge-transport layers. Nat Photon 2014;8:128-32.

[9] Park NG. Perovskite solar cells: an emerging photovoltaic technology. Mater Today 2015;18:65-72.

[10] Green MA, Ho-Baillie A. Perovskite solar cells: the birth of a new era in photovoltaics. ACS Energy Lett 2017;2:822-30.

[11] Elumalai N, Mahmud M, Wang D, Uddin A. Perovskite solar cells: progress and advancements. Energies 2016;9:861.

[12] Shi Z, Jayatissa A. Perovskites-based solar cells: a review of recent progress, materials and processing methods. Materials 2018;11:729.

[13] Tang H, He S, Peng C. A short progress report on high-efficiency perovskite solar cells. Nanoscale Res Lett 2017;12:410.

[14] Song Z, Watthage SC, Phillips AB, Heben MJ. Pathways toward high-performance perovskite solar cells: review of recent advances in organo-metal halide perovskites for photovoltaic applications. J Photon Energy 2016;6:022001.

[15] Kim BJ, Lee S, Jung HS. Recent progressive efforts in perovskite solar cells toward commercialization. J Mater Chem A 2018:6:12215-36.

[16] Yin WJ, Shi T, Yan Y. Unusual defect physics in CH3NH3PbI3 perovskite solar cell absorber. Appl Phys Lett 2014;104.

[17] Jokar E, Chien C-H, Tsai C-M, Fathi A, Diau EW-G. Robust tin-based perovskite solar cells with hybrid organic cations to attain efficiency approaching 10\%. Adv Mater 2019;31:1804835.

[18] Ke W, Kanatzidis MG. Prospects for low-toxicity lead-free perovskite solar cells. Nat Commun 2019;10:965.

[19] Wu T, Liu X, He X, Wang Y, Meng X, Noda T, et al. Efficient and stable tin-based perovskite solar cells by introducing $\pi$-conjugated Lewis base. Sci China Chem 2019;63:107-15.

[20] Niu G, Guo X, Wang L. Review of recent progress in chemical stability of perovskite solar cells. J Mater Chem A 2015;3:8970-80.

[21] Tai Q, Tang KC, Yan F. Recent progress of inorganic perovskite solar cells. Energy Environ Sci 2019;12:2375-405.

[22] Tian J, Xue Q, Tang X, Chen Y, Li N, Hu Z, et al. Dual interfacial design for efficient $\mathrm{CsPb}_{2} \mathrm{Br}$ perovskite solar cells with improved photostability. Adv Mater 2019;31:1901152.

[23] Wang Y, Zhang T, Kan M, Zhao Y. Bifunctional stabilization of all-inorganic $\alpha$-CsPbI 3 perovskite for $17 \%$ efficiency photovoltaics. J Am Chem Soc 2018;140: 12345-8.

[24] Wang H, Bian H, Jin Z, Zhang H, Liang L, Wen J, et al. Cesium lead mixed-halide perovskites for low-energy loss solar cells with efficiency beyond $17 \%$. Chem Mater 2019;31:6231-8. 
[25] Ye Q, Zhao Y, Mu S, Ma F, Gao F, Chu Z, et al. Cesium lead inorganic solar cell with efficiency beyond 18\% via reduced charge recombination. Adv Mater 2019; $31: 1905143$

[26] Song T-B, Yokoyama T, Aramaki S, Kanatzidis MG. Performance enhancement of lead-free tin-based perovskite solar cells with reducing atmosphere-assisted dispersible additive. ACS Energy Lett 2017;2:897-903.

[27] Schulz P, Cahen D, Kahn A. Halide perovskites: is it all about the interfaces? Chem Rev 2019;119:3349-417.

[28] Jiang Q, Zhang X, You J. $\mathrm{SnO}_{2}$ : a wonderful electron transport layer for perovskite solar cells. Small 2018;14:1801154.

[29] Zhang R, Chen Y, Xiong J, Liu X. Synergistic carbon-based hole transporting layers for efficient and stable perovskite solar cells. J Mater Sci 2018;53:4507-14.

[30] Habisreutinger SN, Nicholas RJ, Snaith HJ. Carbon nanotubes in perovskite solar cells. Adv Energy Mater 2017;7:1601839.

[31] Fang Y, Bi C, Wang D, Huang J. The functions of fullerenes in hybrid perovskite solar cells. ACS Energy Lett 2017;2:782-94.

[32] Petridis C, Kakavelakis G, Kymakis E. Renaissance of graphene-related materials in photovoltaics due to the emergence of metal halide perovskite solar cells. Energy Environ Sci 2018;11:1030-61.

[33] Lim EL, Yap CC, Jumali MHH, Teridi MAM, Teh CH. A mini review: can graphene Be a novel material for perovskite solar cell applications? Nano-Micro Lett 2018; 10:27.

[34] Acik M, Darling SB. Graphene in perovskite solar cells: device design, characterization and implementation. J Mater Chem A 2016;4:6185-235.

[35] Wang R, Mujahid M, Duan Y, Wang Z-K, Xue J, Yang Y. A review of perovskites solar cell stability. Adv Funct Mater 2019;29:47-1808843.

[36] Sum TC, Mathews N. Advancements in perovskite solar cells: photophysics behind the photovoltaics. Energy Environ Sci 2014;7:2518-34.

[37] Askar AM, Shankar K. Exciton binding energy in organic-inorganic tri-halide perovskites. J Nanosci Nanotechnol 2016;16:5890-901.

[38] D'Innocenzo V, Grancini G, Alcocer MJP, Kandada ARS, Stranks SD, Lee MM, et al. Excitons versus free charges in organo-lead tri-halide perovskites. Nat Commun 2014:5.

[39] Xing G, Mathews N, Sun S, Lim SS, Lam YM, Gräzel M, et al. Long-range balanced electron-and hole-transport lengths in organic-inorganic CH3NH3PbI3. Science 2013;342:344-7.

[40] Wojciechowski K, Stranks SD, Abate A, Sadoughi G, Sadhanala A, Kopidakis N, et al. Heterojunction modification for highly efficient organic-inorganic perovskite solar cells. ACS Nano 2014;8:12701-9.

[41] Shen D, Zhang W, Xie F, Li Y, Abate A, Wei M. Graphene quantum dots decorated TiO2 mesoporous film as an efficient electron transport layer for highperformance perovskite solar cells. J Power Sources 2018;402:320-6.

[42] Marchioro A, Teuscher J, Friedrich D, Kunst M, Van De Krol R, Moehl T, et al. Unravelling the mechanism of photoinduced charge transfer processes in lead iodide perovskite solar cells. Nat Photon 2014;8:250-5.

[43] Wang L, McCleese C, Kovalsky A, Zhao Y, Burda C. Femtosecond time-resolved transient absorption spectroscopy of $\mathrm{CH}_{3} \mathrm{NH}_{3} \mathrm{PbI}_{3}$ perovskite films: evidence for passivation effect of PbI 2. J Am Chem Soc 2014;136:12205-8.

[44] Serpetzoglou E, Konidakis I, Kakavelakis G, Maksudov T, Kymakis E, Stratakis E. Improved carrier transport in perovskite solar cells probed by femtosecond transient absorption spectroscopy. ACS Appl Mater Interfaces 2017;9:43910-9.

[45] Zhu Z, Ma J, Wang Z, Mu C, Fan Z, Du L, et al. Efficiency enhancement of perovskite solar cells through fast electron extraction: the role of graphene quantum dots. J Am Chem Soc 2014;136:3760-3.

[46] DeQuilettes DW, Vorpahl SM, Stranks SD, Nagaoka H, Eperon GE, Ziffer ME, et al. Impact of microstructure on local carrier lifetime in perovskite solar cells. Science 2015;348:683-6.

[47] Stavrakas C, Delport G, Zhumekenov AA, Anaya M, Chahbazian R, Bakr OM, et al. Visualizing buried local carrier diffusion in halide perovskite crystals via twophoton microscopy. ACS Energy Lett 2019;117-23.

[48] deQuilettes DW, Jariwala S, Burke S, Ziffer ME, Wang JT-W, Snaith HJ, et al. Tracking photoexcited carriers in hybrid perovskite semiconductors: trapdominated spatial heterogeneity and diffusion. ACS Nano 2017;11:11488-96.

[49] Yamashita D, Handa T, Ihara T, Tahara H, Shimazaki A, Wakamiya A, et al. Charge injection at the heterointerface in perovskite $\mathrm{CH}_{3} \mathrm{NH}_{3} \mathrm{PbI}{ }_{3}$ solar cells studied by simultaneous microscopic photoluminescence and photocurrent imaging spectroscopy. J Phys Chem Lett 2016;7:3186-91.

[50] Liu Z, Lau SP, Yan F. Functionalized graphene and other two-dimensional materials for photovoltaic devices: device design and processing. Chem Soc Rev 2015;44:5638-79.

[51] Scarpa F, Adhikari S, Gil AJ, Remillat C. The bending of single layer graphene sheets: the lattice versus continuum approach. Nanotechnology 2010;21: $12-125702$.

[52] Mahmoudi T, Wang Y, Hahn YB. Graphene and its derivatives for solar cells application. Nanomater Energy 2018;47:51-65.

[53] Wu J, Lu Y, Feng S, Wu Z, Lin S, Hao Z, et al. The interaction between quantum dots and graphene: the applications in graphene-based solar cells and photodetectors. Adv Funct Mater 2018;28:1804712.

[54] Filip J, Tkac J. Is graphene worth using in biofuel cells? Electrochim Acta 2014; 136:340-54.

[55] Liu J, Xue Y, Gao Y, Yu D, Durstock M, Dai L. Hole and electron extraction layers based on graphene oxide derivatives for high-performance bulk heterojunction solar cells. Adv Mater 2012;24:2228-33.

[56] Mahmoudi T, Rho W-Y, Yang H-Y, Silva SRP, Hahn Y-B. Highly conductive and dispersible graphene and its application in P3HT-based solar cells. Chem Commun 2014;50:8705.
[57] Carlo A Di, Cinà L, Agresti A, Kymakis E, Pescetelli S, Kakavelakis G, et al. Efficiency and stability enhancement in perovskite solar cells by inserting lithium-neutralized graphene oxide as electron transporting layer. Adv Funct Mater 2016;26:2686-94.

[58] Liu T, Kim D, Han H, Mohd Yusoff AR Bin, Jang J. Fine-tuning optical and electronic properties of graphene oxide for highly efficient perovskite solar cells. Nanoscale 2015;7:10708-18.

[59] Liu J, Xue Y, Dai L. Sulfated graphene oxide as a hole-extraction layer in highperformance polymer solar cells. J Phys Chem Lett 2012;3:1928-33.

[60] Kim JM, Jang CW, Kim JH, Kim S, Choi SH. Use of AuCl3-doped graphene as a protecting layer for enhancing the stabilities of inverted perovskite solar cells. Appl Surf Sci 2018;455:1131-6.

[61] Yun JM, Yeo JS, Kim J, Jeong HG, Kim DY, Noh YJ, et al. Solution-processable reduced graphene oxide as a novel alternative to PEDOT:PSS hole transport layers for highly efficient and stable Polymer solar cells. Adv Mater 2011;23:4923-8.

[62] Choi E-S, Jeon Y-J, Kim S-S, Kim T-W, Noh Y-J, Kwon S-N, et al, Metal chloridetreated graphene oxide to produce high-performance polymer solar cells. Appl Phys Lett 2015;107:023301.

[63] Mahmoudi T, Seo S, Yang H-Y, Rho W-Y, Wang Y, Hahn Y-B. Efficient bulk heterojunction hybrid solar cells with graphene-silver nanoparticles composite synthesized by microwave-assisted reduction. Nanomater Energy 2016;28: 179-87.

[64] Kim S-H, Lee C-H, Yun J-M, Noh Y-J, Kim S-S, Lee S, et al. Fluorine-functionalized and simultaneously reduced graphene oxide as a novel hole transporting layer for highly efficient and stable organic photovoltaic cells. Nanoscale 2014;6:7183-7.

[65] Yang D, Zhou L, Chen L, Zhao B, Zhang J, Li C. Chemically modified graphene oxides as a hole transport layer in organic solar cells. Chem Commun 2012;48: 8078.

[66] Yang D, Zhou L, Yu W, Zhang J, Li C. Work-function-tunable chlorinated graphene oxide as an anode interface layer in high-efficiency polymer solar cells. Adv Energy Mater 2014;4:1400591.

[67] Stratakis E, Savva K, Konios D, Petridis C, Kymakis E. Improving the efficiency of organic photovoltaics by tuning the work function of graphene oxide hole transporting layers. Nanoscale 2014;6:6925-31.

[68] Feng S, Yang Y, Li M, Wang J, Cheng Z, Li J, et al. High-performance perovskite solar cells engineered by an ammonia modified graphene oxide interfacial layer. ACS Appl Mater Interfaces 2016;8:14503-12.

[69] Wang JT-W, Ball JM, Barea EM, Abate A, Alexander-Webber JA, Huang J, et al. Low-temperature processed electron collection layers of graphene/ $\mathrm{TiO}_{2}$ nanocomposites in thin film perovskite solar cells. Nano Lett 2014;14:724-30.

[70] Han GS, Song YH, Jin YU, Lee J-W, Park N-G, Kang BK, et al. Reduced graphene oxide/mesoporous $\mathrm{TiO}_{2}$ nanocomposite based perovskite solar cells. ACS Appl Mater Interfaces 2015;7:23521-6.

[71] Biccari F, Gabelloni F, Burzi E, Gurioli M, Pescetelli S, Agresti A, et al. Graphenebased electron transport layers in perovskite solar cells: a step-up for an efficient carrier collection. Adv Energy Mater 2017;7:1701349.

[72] O'Keeffe P, Catone D, Paladini A, Toschi F, Turchini S, Avaldi L, et al. Grapheneinduced improvements of perovskite solar cell stability: effects on hot-carriers. Nano Lett 2019;19:684-91.

[73] Tavakoli MM, Tavakoli R, Hasanzadeh S, Mirfasih MH. Interface engineering of perovskite solar cell using a reduced-graphene scaffold. J Phys Chem C 2016;120: 19531-6.

[74] Tavakoli MM, Tavakoli R, Nourbakhsh Z, Waleed A, Virk US, Fan Z. High efficiency and stable perovskite solar cell using $\mathrm{ZnO} / \mathrm{rGO}$ QDs as an electron transfer layer. Adv Mater Interfaces 2016;3:1500790.

[75] Zhao X, Tao L, Li H, Huang W, Sun P, Liu J, et al. Efficient planar perovskite solar cells with improved fill factor via interface engineering with graphene. Nano Lett 2018;18:2442-9.

[76] Zhu M, Liu W, Ke W, Xie L, Dong P, Hao F. Graphene-modified tin dioxide for efficient planar perovskite solar cells with enhanced electron extraction and reduced hysteresis. ACS Appl Mater Interfaces 2019;11:666-73.

[77] Kakavelakis G, Maksudov T, Konios D, Paradisanos I, Kioseoglou G, Stratakis E, et al. Efficient and highly air stable planar inverted perovskite solar cells with reduced graphene oxide doped PCBM electron transporting layer. Adv Energy Mater 2017;7.

[78] Nouri E, Mohammadi MR, Lianos P. Inverted perovskite solar cells based on lithium-functionalized graphene oxide as an electron-transporting layer. Chem Commun 2017:53:1630-3.

[79] Nouri E, Mohammadi MR, Lianos P. Improving the stability of inverted perovskite solar cells under ambient conditions with graphene-based inorganic charge transporting layers. Carbon N Y 2018;126:208-14.

[80] Kim M, Yoon H, Jeon I-Y, Baek J-B, Kim DS, Yoon YJ, et al. Fluorine functionalized graphene nano platelets for highly stable inverted perovskite solar cells. Nano Lett 2017;17:6385-90.

[81] Li W, Dong H, Wang L, Li N, Guo X, Li J, et al. Montmorillonite as bifunctional buffer layer material for hybrid perovskite solar cells with protection from corrosion and retarding recombination. J Mater Chem A 2014;2:13587-92.

[82] Hawash Z, Ono LK, Qi Y. Recent advances in spiro-MeOTAD hole transport material and its applications in organic-inorganic halide perovskite solar cells. Adv Mater Interfaces 2018;5:1.

[83] Li W, Dong H, Guo X, Li N, Li J, Niu G, et al. Graphene oxide as dual functional interface modifier for improving wettability and retarding recombination in hybrid perovskite solar cells. J Mater Chem A 2014;2:20105-11.

[84] Li H, Tao L, Huang F, Sun Q, Zhao X, Han J, et al. Enhancing efficiency of perovskite solar cells via surface passivation with graphene oxide interlayer. ACS Appl Mater Interfaces 2017;9:38967-76. 
[85] Luo Q, Zhang Y, Liu C, Li J, Wang N, Lin H. Iodide-reduced graphene oxide with dopant-free spiro-OMeTAD for ambient stable and high-efficiency perovskite solar cells. J Mater Chem A 2015;3:15996-6004.

[86] Wen X, Wu J, Gao D, Lin C. Interfacial engineering with amino-functionalized graphene for efficient perovskite solar cells. J Mater Chem A 2016;4:13482-7.

[87] Cao J, Liu Y-M, Jing X, Yin J, Li J, Xu B, et al. Well-defined thiolated nanographene as hole-transporting material for efficient and stable perovskite solar cells. J Am Chem Soc 2015;137:10914-7.

[88] Pescetelli S, Di Carlo A, Raggio M, Agresti A, Bonaccorso F, Cinà L, et al. Reduced graphene oxide as efficient and stable hole transporting material in mesoscopic perovskite solar cells. Nanomater Energy 2016;22:349-60.

[89] Lee DY, Na SI, Kim SS. Graphene oxide/PEDOT:PSS composite hole transport layer for efficient and stable planar heterojunction perovskite solar cells. Nanoscale 2016;8:1513-22.

[90] Wu Z, Bai S, Xiang J, Yuan Z, Yang Y, Cui W, et al. Efficient planar heterojunction perovskite solar cells employing graphene oxide as hole conductor. Nanoscale 2014;6:10505-10.

[91] Yeo JS, Kang R, Lee S, Jeon YJ, Myoung NS, Lee CL, et al. Highly efficient and stable planar perovskite solar cells with reduced graphene oxide nanosheets as electrode interlayer. Nanomater Energy 2015;12:96-104.

[92] Jokar E, Huang ZY, Narra S, Wang CY, Kattoor V, Chung CC, et al. Anomalous charge-extraction behavior for graphene-oxide (GO) and reduced graphene-oxide (rGO) films as efficient p-contact layers for high-performance perovskite solar cells. Adv Energy Mater 2018;8:1-10.

[93] Liang PW, Chueh CC, Williams ST, Jen AKY. Roles of fullerene-based interlayers in enhancing the performance of organometal perovskite thin-film solar cells. Adv Energy Mater 2015;5:1-7.

[94] Zhang K, Yu H, Liu X, Dong Q, Wang Z, Wang Y, et al. Fullerenes and derivatives as electron transport materials in perovskite solar cells. Sci China Chem 2017;60: 144-50.

[95] Wang Q, Shao Y, Dong Q, Xiao Z, Yuan Y, Huang J. Large fill-factor bilayer iodine perovskite solar cells fabricated by a low-temperature solution-process. Energy Environ Sci 2014:7:2359-65.

[96] Gatti T, Menna E, Meneghetti M, Maggini M, Petrozza A, Lamberti F. The Renaissance of fullerenes with perovskite solar cells. Nanomater Energy 2017;41: 84-100.

[97] Lin HK, Su YW, Chen HC, Huang YJ, Wei KH. Block copolymer-tuned fullerene electron transport layer enhances the efficiency of perovskite photovoltaics. ACS Appl Mater Interfaces 2016;8:24603-11.

[98] Page ZA, Liu Y, Duzhko VV, Russell TP, Emrick T. Fulleropyrrolidine interlayers: tailoring electrodes to raise organic solar cell efficiency. Science 2014;346:441-4. 80-.

[99] Duzhko VV, Dunham B, Rosa SJ, Cole MD, Paul A, Page ZA, et al. N-doped zwitterionic fullerenes as interlayers in organic and perovskite photovoltaic devices. ACS Energy Lett 2017;2:957-63.

[100] Shao Y, Xiao Z, Bi C, Yuan Y, Huang J. Origin and elimination of photocurrent hysteresis by fullerene passivation in CH3NH3PbI3 planar heterojunction solar cells. Nat Commun 2014;5:5784.

[101] Liu D, Wang Q, Traverse CJ, Yang C, Young M, Kuttipillai PS, et al. Impact of ultrathin C60 on perovskite photovoltaic devices. ACS Nano 2018;12:876-83.

[102] Chao Y-H, Huang Y-Y, Chang J-Y, Peng S-H, Tu W-Y, Cheng Y-J, et al. A crosslinked fullerene matrix doped with an ionic fullerene as a cathodic buffer layer toward high-performance and thermally stable polymer and organic metallohalide perovskite solar cells. J Mater Chem A 2015;3:20382-8.

[103] Yang M, Zhao D, Fang G, Zhu K, Li Z, Kanatzidis MG, et al. Cooperative tin oxide fullerene electron selective layers for high-performance planar perovskite solar cells. J Mater Chem A 2016;4:14276-83.

[104] Eze VO, Seike Y, Mori T. Efficient planar perovskite solar cells using solutionprocessed amorphous WO x/fullerene C 60 as electron extraction layers. Org Electron 2017;46:253-62.

[105] Wojciechowski K, Ramirez I, Gorisse T, Dautel O, Dasari R, Sakai N, et al. Crosslinkable fullerene derivatives for solution-processed n-i-p perovskite solar cells. ACS Energy Lett 2016;1:648-53.

[106] Topolovsek P, Lamberti F, Gatti T, Cito A, Ball JM, Menna E, et al. Functionalization of transparent conductive oxide electrode for $\mathrm{TiO}_{2}$-free perovskite solar cells. J Mater Chem A 2017;5:11882-93.

[107] Collavini S, Kosta I, Völker SF, Cabanero G, Grande HJ, Tena-Zaera R, et al. Efficient regular perovskite solar cells based on pristine [70]Fullerene as electronselective contact. ChemSusChem 2016;9:1263-70.

[108] Lin HS, Jeon I, Xiang R, Seo S, Lee JW, Li C, et al. Achieving high efficiency in solution-processed perovskite solar cells using C60/C70 mixed fullerenes. ACS Appl Mater Interfaces 2018;10:39590-8.

[109] Wang F, Matsuda K. Applications of carbon nanotubes in solar cells. In: Nanocarbons energy convers. Supramol. Approaches. Springer International Publishing; 2019. p. 497-536.

[110] Ihly R, Dowgiallo A-M, Yang M, Schulz P, Stanton NJ, Reid OG, et al. Efficient charge extraction and slow recombination in organic-inorganic perovskites capped with semiconducting single-walled carbon nanotubes. Energy Environ Sci 2016:9:1439-49.

[111] Cai M, Tiong VT, Hreid T, Bell J, Wang H. An efficient hole transport material composite based on poly(3-hexylthiophene) and bamboo-structured carbon nanotubes for high performance perovskite solar cells. J Mater Chem A 2015;3: 2784-93.

[112] Miletić T, Pavoni E, Trifiletti V, Rizzo A, Listorti A, Colella S, et al. Covalently functionalized SWCNTs as tailored p-type dopants for perovskite solar cells. ACS Appl Mater Interfaces 2016;8:27966-73.
[113] Wang J, Li J, Xu X, Xu G, Shen H. Enhanced photovoltaic performance with carbon nanotubes incorporating into hole transport materials for perovskite solar cells. J Electron Mater 2016;45:5127-32.

[114] Lee J, Menamparambath MM, Hwang J-Y, Baik S. Hierarchically structured hole transport layers of spiro-OMeTAD and multiwalled carbon nanotubes for perovskite solar cells. ChemSusChem 2015;8:2358-62.

[115] Zhang S, Wang X, Xu W, Wong LH, Kulkarni SA, Li Z, et al. TiO2 nanotube arrays based flexible perovskite solar cells with transparent carbon nanotube electrode. Nanomater Energy 2014;11:728-35.

[116] Aitola K, Sveinbjörnsson K, Correa-Baena JP, Kaskela A, Abate A, Tian Y, et al. Carbon nanotube-based hybrid hole-transporting material and selective contact for high efficiency perovskite solar cells. Energy Environ Sci 2016:9:461-6.

[117] Aitola K, Domanski K, Correa-Baena JP, Sveinbjörnsson K, Saliba M, Abate A, et al. High temperature-stable perovskite solar cell based on low-cost carbon nanotube hole contact. Adv Mater 2017;29:1-5.

[118] Tiong VT, Pham ND, Wang T, Zhu T, Zhao X, Zhang Y, et al. Octadecylaminefunctionalized single-walled carbon nanotubes for facilitating the formation of a monolithic perovskite layer and stable solar cells. Adv Funct Mater 2018;28:1-14.

[119] Habisreutinger SN, Leijtens T, Eperon GE, Stranks SD, Nicholas RJ, Snaith HJ. Enhanced hole extraction in perovskite solar cells through carbon nanotubes. J Phys Chem Lett 2014;5:4207-12.

[120] Mazzotta G, Dollmann M, Habisreutinger SN, Christoforo MG, Wang Z, Snaith HJ, et al. Solubilization of carbon nanotubes with ethylene-vinyl acetate for solutionprocessed conductive films and charge extraction layers in perovskite solar cells. ACS Appl Mater Interfaces 2019;11:1185-91.

[121] Habisreutinger SN, Leijtens T, Eperon GE, Stranks SD, Nicholas RJ, Snaith HJ. Carbon nanotube/polymer composites as a highly stable hole collection layer in perovskite solar cells. Nano Lett 2014;14:5561-8.

[122] Wang F, Endo M, Mouri S, Miyauchi Y, Ohno Y, Wakamiya A, et al. Highly stable perovskite solar cells with an all-carbon hole transport layer. Nanoscale 2016;8: $11882-8$.

[123] Yan Y, Gong J, Chen J, Zeng Z, Huang W, Pu K, et al. Recent advances on graphene quantum dots: from chemistry and physics to applications. Adv Mater 2019;1808283:1808283.

[124] Yang Z, Hu M, Qiang Y, Huang K, Yu X, Cui C, et al. Efficient and highly light stable planar perovskite solar cells with graphene quantum dots doped PCBM electron transport layer. Nanomater Energy 2017;40:345-51.

[125] Yang D, Xiao K, Xu L, Huang K, Wang P, Cui C, et al. Enhanced electronic properties of SnO 2 via electron transfer from graphene quantum dots for efficient perovskite solar cells. ACS Nano 2017;11:9176-82.

[126] Zhou Y, Yang S, Yin X, Han J, Tai M, Zhao X, et al. Enhancing electron transport via graphene quantum dot/SnO 2 composites for efficient and durable flexible perovskite photovoltaics. J Mater Chem A 2019;7:1878-88.

[127] Kwon W, Kim Y-H, Lee C-L, Lee M, Choi HC, Lee T-W, et al. Electroluminescence from graphene quantum dots prepared by amidative cutting of tattered graphite. Nano Lett 2014;14:1306-11.

[128] Yeh T-F, Huang W-L, Chung C-J, Chiang I-T, Chen L-C, Chang H-Y, et al. Elucidating quantum confinement in graphene oxide dots based on excitationwavelength-independent photoluminescence. J Phys Chem Lett 2016;7:2087-92.

[129] Ryu J, Lee JW, Yu H, Yun J, Lee K, Lee J, et al. Size effects of a graphene quantum dot modified-blocking TiO2 layer for efficient planar perovskite solar cells. J Mater Chem A 2017;5:16834-42.

[130] Tetsuka H, Nagoya A, Fukusumi T, Matsui T. Molecularly designed, nitrogenfunctionalized graphene quantum dots for optoelectronic devices. Adv Mater 2016;28:4632-8.

[131] Sciortino A, Cannizzo A, Messina F. Carbon nanodots: a review-from the current understanding of the fundamental photophysics to the full control of the optical response. Chimia 2018:4:67.

[132] Paulo S, Palomares E, Martinez-Ferrero E. Graphene and carbon quantum dotbased materials in photovoltaic devices: from synthesis to applications. Nanomaterials 2016:6:157.

[133] Li X, Rui M, Song J, Shen Z, Zeng H. Carbon and graphene quantum dots for optoelectronic and energy devices: a review. Adv Funct Mater 2015;25:4929-47.

[134] Jin J, Chen C, Li H, Cheng Y, Xu L, Dong B, et al. Enhanced performance and photostability of perovskite solar cells by introduction of fluorescent carbon dots. ACS Appl Mater Interfaces 2017;9:14518-24.

[135] Li H, Shi W, Huang W, Yao EP, Han J, Chen Z, et al. Carbon quantum dots/TiOx electron transport layer boosts efficiency of planar heterojunction perovskite solar cells to 19\%. Nano Lett 2017;17:2328-35.

[136] Paulo S, Stoica G, Cambarau W, Martinez-Ferrero E, Palomares E. Carbon quantum dots as new hole transport material for perovskite solar cells. Synth Met 2016;222:17-22.

[137] Cui H, Bi Y, Liu C, Guo J, Shen L, Li Z, et al. Using easily prepared carbon nanodots to improve hole transport capacity of perovskite solar cells. Mater Today Energy 2019;12:161-7.

[138] Ding J, Yuan N, Ding G, Sun P, Fang X, Lv M, et al. Graphene quantum dot incorporated perovskite films: passivating grain boundaries and facilitating electron extraction. Phys Chem Chem Phys 2017;19:6057-63.

[139] Zhang J, Tong T, Zhang L, Li X, Zou H, Yu J. Enhanced performance of plana perovskite solar cell by graphene quantum dot modification. ACS Sustainable Chem Eng 2018;6:8631-40.

[140] Ma Y, Zhang H, Zhang Y, Hu R, Jiang M, Zhang R, et al. Enhancing the performance of inverted perovskite solar cells via grain boundary passivation with carbon quantum dots. ACS Appl Mater Interfaces 2019;11:3044-52. 